\title{
Induction via Functional Protein Stabilization of Hepatic Cytochromes P450 upon gp78/Autocrine Motility Factor Receptor (AMFR) Ubiquitin E3-Ligase Genetic Ablation in Mice: Therapeutic and Toxicological Relevance
}

\author{
Doyoung Kwon, Sung-Mi Kim, Peyton Jacob, Yi Liu III, and Maria Almira Correia
}

\begin{abstract}
Departments of Cellular and Molecular Pharmacology (D.K., S.-M.K., Y.L., M.A.C.), Pharmaceutical Chemistry (M.A.C.), and Bioengineering and Therapeutic Sciences (M.A.C.) and The Liver Center (M.A.C.), University of California San Francisco, San Francisco, California; and Clinical Pharmacology Program, Division of Cardiology, Department of Medicine, Center for Tobacco Control Research and Education, University of California, San Francisco, California (P.J.)
\end{abstract}

Received May 1, 2019; accepted August 22, 2019

\section{ABSTRACT}

The hepatic endoplasmic reticulum (ER)-anchored monotopic proteins, cytochromes P450 (P450s), are enzymes that metabolize endobiotics (physiologically active steroids and fatty acids), as well as xenobiotics including therapeutic/chemotherapeutic drugs, nutrients, carcinogens, and toxins. Alterations of hepatic P450 content through synthesis, inactivation, or proteolytic turnover influence their metabolic function. P450 proteolytic turnover occurs via ER-associated degradation (ERAD) involving ubiquitin (Ub)-dependent proteasomal degradation (UPD) as a major pathway. UPD critically involves $P 450$ protein ubiquitination by E2/E3 Ub-ligase complexes. We have previously identified the ER-polytopic gp78/AMFR (autocrine motility factor receptor) as a relevant E3 in CYP3A4, CYP3A23, and CYP2E1 UPD. We now document that liver-conditional genetic ablation of gp78/ AMFR in male mice disrupts P450 ERAD, resulting in statistically significant stabilization of Cyp2a5 and Cyp2c, in addition to that of Cyp3a and Cyp2e1. More importantly, we establish that such stabilization is of the functionally active P450 proteins, leading to corresponding statistically significant enhancement of their drugmetabolizing capacities. Our findings, with clinically relevant therapeutic drugs (nicotine, coumarin, chlorzoxazone, and acetaminophen) and the prodrug (tamoxifen) as P450 substrates, reveal that $P 450$ ERAD disruption could influence therapeutic drug response and/or toxicity, warranting serious consideration as a potential source of clinically relevant drug-drug interactions (DDIs). Because gp78/AMFR is not only an E3 Ub-ligase, but also a cell-surface prometastatic oncogene that is upregulated in various malignant cancers, our finding that hepatic gp78/AMFR knockout can enhance P450-dependent bioactivation of relevant cancer chemotherapeutic prodrugs is of therapeutic relevance and noteworthy in prospective drug design and development.

\section{SIGNIFICANCE STATEMENT}

The cell-surface and ER transmembrane protein gp78/AMFR, a receptor for the prometastatic autocrine motility factor (AMF), as well as an E3 ubiquitin-ligase involved in the ER-associated degradation (ERAD) of not only the tumor metastatic suppressor KAl1 but also of hepatic cytochromes P450, is upregulated in various human cancers, enhancing their invasiveness, metastatic potential, and poor prognosis. Liver-specific gp78/AMFR genetic ablation results in functional protein stabilization of several hepatic P450s and consequently enhanced drug and prodrug metabolism, a feature that could be therapeutically exploited in the bioactivation of chemotherapeutic prodrugs through design and development of novel short-term gp78/ AMFR chemical inhibitors.
This work was supported by the National Institutes of Health (Grants GM44037 and DK26506 to M.A.C.).

This was presented in poster form and in one of the ASPET "Data Blitzes" at the 2018 Experimental Biology; April 21-25, 2018, San Diego, CA; Abstract C148. An earlier version of this paper appears in bioRxiv at https://doi.org/10. 1101/623041v1; posted April 30, 2019.

https://doi.org/10.1124/mol.119.117069.

\section{Introduction}

Luminal and membrane-bound endoplasmic reticulum (ER) proteins incur proteolytic turnover via ubiquitin (Ub)-dependent proteasomal degradation (UPD) in a physiologic process termed "ER-associated degradation" (ERAD) (Olzmann et al., 2013; Christianson and Ye, 2014; Preston

ABBREVIATIONS: ALD, autophagy-lysosomal degradation; ALT, alanine aminotransferase; AMF, autocrine motility factor; AMFR, AMF-receptor; APAP, acetaminophen; CEC, 3-cyano-7-ethoxycoumarin; cgt, conditional gene trap; CHIP, carboxy-terminus of Hsc70-interacting protein; Cre, Cre-recombinase; Ct, threshold cycle; DDIs, drug-drug interactions; DEX, dexamethasone; ER, endoplasmic reticulum; ERAD, ER-associated degradation; flp, floxed; Flpe, flippase; FMO3, flavin-monooxygenase; HPLC-MS, high-performance liquid chromatography-mass spectrometry; IB, immunoblotting; INH, isoniazid; KO, knockout; 3-MA, 3-methyladenine; MDA, malondialdehyde; MFC, 7-methoxy-4-(trifluoromethyl)-coumarin; NAPQI, N-acetylparaquinoneimine; NASH, nonalcoholic steatohepatitis; NNK, 4-(methylnitrosamino)-1-(3-pyridyl)-1-butanone; P450, cytochrome P450; PB, phenobarbital; PCR, polymerase chain reaction; shRNAi, short-hairpin RNA interference; Ub, ubiquitin; UPD, Ub-dependent proteasomal degradation; WT, wild type. 
and Brodsky, 2017; Needham et al., 2019). This vital process is critical for the protein quality control required to mitigate the unfolded protein response triggered by ER stress and/or other cellular stresses, as well as for the normal physiologic ER-protein turnover (Olzmann et al., 2013; Christianson and Ye, 2014; Preston and Brodsky, 2017). Accordingly, we have found that the hepatic monotopic ER-anchored cytochromes P450 (P450s; CYPs) incur ERAD not just upon their mechanism-based inactivation that structurally damages the proteins but also in the course of their physiologic turnover (Correia et al., 1992; Wang et al., 1999; Faouzi et al., 2007). Human hepatic P450s are responsible for the metabolism and elimination of approx. $74 \%$ of therapeutically relevant drugs and participate in many drug-drug interactions (DDIs) and drug-related toxicities (Guengerich, 2015; Correia, 2018). The ERAD of human and rat hepatic P450s CYP3A4, CYP3A23, and CYP2E1 involves an initial Ser/Thr-phosphorylation by protein kinases A and C (Eliasson et al., 1992, 1994; Wang et al., 2001, 2009, 2011, 2012, 2015), their ubiquitination via Ub-activation enzymes E1 and E2/E3-Ub conjugation complexes (Morishima et al., 2005; Pabarcus et al., 2009; Wang et al., 2009, 2011, 2012; Kim et al., 2010), their extraction from the ER by p97/Ufd1/Npl4-AAA ATPase complex, and subsequent delivery to the 26S proteasome (Liao et al., 2006; Faouzi et al., 2007; Acharya et al., 2011).

In vitro functional reconstitution studies (Morishima et al., 2005; Pabarcus et al., 2009; Kim et al., 2010) of E1/E2/E3mediated CYP3A4 and CYP2E1 ubiquitination have led to the identification of UbcH5a/Hsp70/CHIP and UBC7/gp78/AMFR complexes as two relevant E2/E3 systems in CYP3A4 and CYP2E1 ubiquitination: CHIP (carboxy-terminus of Hsc70interacting protein), a cytoplasmic Hsc70-cochaperone, functions with its cognate UbcH5a E2 and Hsc70/Hsp70 in substrate ubiquitination (Ballinger at al., 1999; Connell et al., 2001; Jiang et al., 2001; Murata et al., 2001). gp78/AMFR (autocrine motility factor receptor) is a polytopic, transmembrane cell surface protein (Nabi et al., 1990), as well as an ER-integral protein with a cytoplasmic domain containing a RING-finger and other subdomains critical to its recruitment of its cognate E2 (UBC7 or Ube2G2) and catalytic E3ligase-mediated ubiquitination role (Fang et al., 2001; Zhong et al., 2004; Chen et al., 2006, 2012; Joshi et al., 2017).

Our lentiviral short-hairpin RNA interference (shRNAi) analyses targeted individually against CHIP and gp78 verified their roles in CYP3A and CYP2E1 ubiquitination and ERAD in cultured rat hepatocytes (Kim et al., 2010). Thus, upon CHIP knockdown, CYP3A was stabilized largely as the parent $(55-\mathrm{kDa})$ species along with a minor CYP3A fraction consisting of its high molecular mass ubiquitinated species. Similar stabilization of CYP3A parent species was also found upon gp78 knockdown, albeit with an appreciable fraction as its ubiquitinated species. Nevertheless, upon either E3 knockdown of CHIP or gp78, the functionally active CYP3A fraction, albeit proportional to the relative amount of the stabilized parent protein, was statistically significantly greater than that in the corresponding control (nontargeting) shRNAtreated hepatocytes (Kim et al., 2010). Furthermore, in vitro reconstitution studies of each CYP3A4 E2/E3-ubiquitination system, individually and in combination, revealed that although each system by itself was capable of CYP3A4 ubiquitination, this was both greatly accelerated and potentiated when both systems were present simultaneously (Wang et al.,
2015). Thus, the sequential introduction of each E2/E3 in the reconstituted CYP3A4-ubiquitination system revealed that UbcH5a/CHIP most probably serves as the E3, whereas UBC7/gp78 serves as the E4 involved in the elongation of CYP3A4 polyUb chains (Wang et al., 2015).

Consistent with shRNAi findings, Cyp2e1 was also stabilized in a functionally active form upon mouse CHIP knockout (KO) (Kim et al., 2016a). This functional Cyp2e1 stabilization was associated with increased hepatic lipid peroxidation, microvesicular steatosis, and eventually, upon aging, with macrovesicular steatosis and liver injury characteristic of the nonalcoholic steatohepatitis (NASH) syndrome (Kim et al., 2016a).

To determine whether genetic ablation of gp78, the other E3 Ub-ligase identified as relevant to hepatic CYP3A4 and CYP2E1 ERAD, had similar consequences, we generated a mouse liver-conditional gp78-KO (gp78 ${ }^{-/-}$) model. This gp $78^{-1-}$ model enabled us not only to examine the role of gp78-mediated ubiquitination in the ERAD and consequent physiologic function of Cyps $3 \mathrm{a}$ and Cyp2e1 but also to identify additional hepatic $\mathrm{P} 450 \mathrm{~s}$ as potential gp78-ubiquitination targets and to determine their therapeutic/toxicological consequences. Our findings are described herein.

\section{Materials and Methods}

Generation of a Liver-Conditional gp78-KO Mouse. Cryopreserved mouse embryos carrying a conditional amfr ${ }^{\text {tma } 1 \text { (Komp)Wtsi }}$ genetrap knockout-first allele inserted into amfr intron 2 with loxP sites flanking exon 3 of amfr were generated as described (Skarnes et al., 2011; Bradley et al., 2012), resuscitated, cultured, and transplanted into oviducts of pseudopregnant females of C57BL/6J-Tyrc-Brd; C57BL/6N background, at the UC Davis Knockout Mouse Project Facility. Upon weaning, the heterozygous conditional gene-trap (cgt) genotype of the pups was confirmed by polymerase chain reaction (PCR) analyses. Mice aged 6 weeks were shipped to UCSF LARC Transgenic Barrier Facility, where the loxP-flanking sequence was deleted through mating of 8-week-old heterozygous females with transgenic male mice (C57BL/6J-background) carrying Flpe (flippase) recombinase driven by the $\beta$-actin promoter (Flpe-deleter; $\beta$-actinFlp), and of corresponding heterozygous males with female Flpe-mice. After several intercrosses, homozygous gp78-floxed (flp/flp) mice were obtained. To generate liver-specific gp78 KOs, flp/flp mice were crossbred with Alb-Cre-recombinase (Cre)/Alb-Cre (B6.Cg-Tg(Albcre) $21 \mathrm{Mgn} / \mathrm{J}$ ) mice (Postic and Magnuson, 2000). The resulting flp/+, Alb-Cre/+ mice were then crossed again with flp/flp mice to generate flp/flp, Alb-Cre/+ mice as liver-specific gp78 KOs. The primers (Tables 1 and 2) used for the tail-clip genotyping were located as indicated by the arrows (Fig. 1A). Mice were fed a standard chow diet and maintained under 12-hour light/dark cycle. All animal experimental protocols were approved by the UCSF/Institutional Animal Care and Use Committee.

Primary Mouse Hepatocyte Cultures. Male mice, 8 to 9 weeks of age, were used throughout because in our preliminary studies, specific hepatic Cyp3a isoforms exhibited sex-dependent differences in content upon liver-conditional gp78-ablation (S.M. Kim and M.A. Correia, unpublished findings). Hepatocyte isolation from male

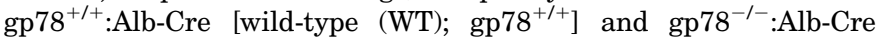
(KO; gp $78^{-/-}$) mice was carried out by in situ liver perfusion with collagenase and purification by Percoll-gradient centrifugation by the UCSF Liver Center Cell Biology Core as described previously (Han et al., 2005). In a few studies, freshly isolated primary hepatocytes were used for monitoring the basal, hepatic constitutive P450 isoform content (see below). Alternatively, freshly isolated hepatocytes were cultured $\left(3.0 \times 10^{6}\right.$ cells/plate) on 60 -mm Permanox plates (Thermo Fisher Scientific, Waltham, MA) coated with Type I collagen, and incubated in William's E Medium containing $2 \mathrm{mM}$ L-glutamine, 
TABLE 1

Summary of the primer sequences used for genotyping

\begin{tabular}{ll}
\hline Primer Name & \multicolumn{1}{c}{${\text { Nucleotide Sequence }\left(5^{\prime}-3^{\prime}\right)}^{\prime}$ 1: CSD- LoxP-common forward } \\
2: Gene-specific reverse (SR1) & GAGATGGCGCAACGCAATTAAT \\
3: WT-F & CAGAGATTCTACCTCCTGAGTGCTGG \\
4: WT-TTR & GGATCTGAAATCACTGAGCAGTGC \\
5: CSD-LoxF & TGTACATGTTCCTTCATGTGAGGAAG \\
6: CSD-Amfr-R & GAGATGGCGCAACGCAATTAATG \\
flpF & ACCTCCTGAGTGCTGGGATTAAAGG \\
flpR & CACCTAAGGTCCTGGTTCGTCA \\
creF & CCCAGATGCTTTCACCCTCACT \\
creR & CATTTGGGCCAGCTAAACAT \\
\hline
\end{tabular}

cre, Cre-recombinase; F, forward; R, reverse.

penicillin-streptomycin, insulin-transferrin-selenium, $0.1 \%$ bovine serum albumin fraction $\mathrm{V}$, and $0.1 \mu \mathrm{M}$ dexamethasone (DEX). Cells were allowed to attach to the plates for 6 hours, before Matrigel (Matrigel Matrix; Corning Inc., New York) was overlaid and cell cultures allowed to stabilize for 2 days, during which the initial basal P450 content was almost completely lost. To restore functional P450 cellular content, after a 2-day stabilization, cultured primary hepatocytes were treated for 3 days with the following P450-inducers: $\beta$-naphthoflavone $(\beta$-NF; $25 \mu \mathrm{M}$; Cyp1a2), phenobarbital (PB; $1 \mathrm{mM}$; Cyps 2a, $2 \mathrm{~b}$ and $2 \mathrm{c}$ ), DEX (10 $\mu \mathrm{M}$; Cyps 3a), and isoniazid (INH; $1 \mathrm{mM}$, Cyp2e1).

Determination of Relative P450 Protein Content in Freshly Isolated or Cultured gp78-KO and WT Mouse Hepatocytes. In certain studies, freshly isolated hepatocytes were lysed in cell lysis buffer (Cell Signaling Technology, Inc., Danvers, MA) and directly used for immunoblotting (IB) analyses of constitutive P450s. In others, upon inducer treatment, cultured cells were harvested in the same cell lysis buffer. In either case, cell lysates were cleared by centrifugation $\left(14,000 \mathrm{~g}, 10\right.$ minutes, $\left.4^{\circ} \mathrm{C}\right)$, and $\mathrm{P} 450$ proteins in the supernatant were subjected to Western IB analyses. Commercial primary antibodies were used for detecting Cyp1a2 (mouse monoclonal, cat. no. 14719; Cell Signaling Technology, Inc.), Cyp2a (rabbit polyclonal, cat. no. ab3570; Abcam, Cambridge, UK), and Cyp2d (rabbit polyclonal, cat. no. GTX56286; Genetex, Inc. Irvine, CA). Purified antibodies from rabbit (Cyp2b, Cyp2c, and Cyp2e1) and from goat (Cyps 3a) sera were also used as previously described (Kim et al., 2016a,b). Immunoblots were densitometrically quantified through NIH Image J software analyses.

Relative P450 mRNA Expression in Cultured WT and gp78-KO Mouse Hepatocytes. $\beta$ NF- and INH-pretreated cultured WT and gp78-KO hepatocytes were used for Cyp1a2 and Cyp2e1 mRNA level determination, respectively; PB-pretreated hepatocytes were used for monitoring Cyp2a5, 2b10, 2c29, $2 c 39$, and $2 d 10$ mRNA levels, whereas DEX-pretreated hepatocytes were used for monitoring Cyp3a11 and Cyp3a13 mRNA levels. On day 4, total RNA was extracted from the cultured hepatocytes with RNeasy mini-kit (Qiagen, Hilden, Germany), and cDNA was synthesized using SuperScript IV VILO Master Mix (Thermo Fisher Scientific). Hepatic P450 mRNA expression was determined by quantitative real-time (qRT)-PCR analyses, using SYBR Green PCR Master Mix (Applied Biosystems, Foster City, CA), and monitored by Agilent Mx3005P System (Agilent Technologies, Santa Clara, CA).

\section{TABLE 2}

Summary of the PCR product (amplicon) size for each primer pair and the corresponding genotype represented

\begin{tabular}{lcl}
\hline Primer Pairs & Band Size (bp) & \multicolumn{1}{c}{ Genotype } \\
\hline $1+2$ & 337 & Cgt (conditional gene-trap cassette) \\
$3+4$ & 200 & Wild type (WT) \\
flpF + flpR & 435 & With flpe recombinase (flpe) \\
$5+6$ & 327 & Floxed (fl) \\
creF + creR & 233 & With Cre recombinase \\
\hline
\end{tabular}

cre, Cre-recombinase; F, forward; $R$, reverse.
Relative gene expression level of each P450 was determined by normalizing its threshold cycle $(\mathrm{Ct})$ to that of GAPDH Ct. Primers used are listed (Table 3).

Cyp2a Ubiquitination and Degradation Analyses. Cultured PB-pretreated hepatocytes were subjected to cycloheximide-chase analyses by treatment on day 4 at 0 hour with cycloheximide $50 \mu \mathrm{g} / \mathrm{ml}$ with or without the proteasome inhibitor bortezomib $(10 \mu \mathrm{M})$, or the autophagy-lysosomal degradation (ALD) inhibitors, 3-methyladenine (3-MA; $5 \mathrm{mM} / \mathrm{NH}_{4} \mathrm{Cl} ; 50 \mathrm{mM}$ ) for 0,8 , and 24 hours. Cells were harvested and the lysates were used for Cyp2a IB analyses.

Cyp2a5 ubiquitination analyses were conducted following P450 immunoprecipitation from the lysates ( $200 \mu \mathrm{g}$ protein) of hepatocytes treated with or without bortezomib $(10 \mu \mathrm{M})$ for 8 hours. Immunoprecipitates were incubated with Cyp2a antibody at $4^{\circ} \mathrm{C}$ overnight. The antibody-antigen complexes were captured by incubation with Dynabeads protein $\mathrm{G}$ (Thermo Fisher Scientific) at room temperature for 2 hours and then eluted by heating at $95^{\circ} \mathrm{C}$ for 10 minutes in $2 \times$ volume of SDS-PAGE loading buffer. The ubiquitinated P450s were detected by Western IB analyses with a mouse monoclonal Ub-antibody (cat. no. ab7254; Abcam plc), as described previously (Wang et al., 1999, 2015; Kim et al., 2010).

Fluorescence-Based Screening of P450 Functional Markers in Cultured Mouse Hepatocytes. P450 functional activities in cultured primary hepatocytes were determined by the method of Donato et al. (2004), as previously described (Kim et al., 2010). On day 4 after P450-inducer pretreatment, hepatocytes were incubated with P450 substrates, 3-cyano-7-ethoxycoumarin (CEC, $30 \mu \mathrm{M}$; Cyp1a2; cat. no. 451014.; Corning Inc.), coumarin (CM, $50 \mu \mathrm{M}$; Cyp2a5; cat. no., C4261; Sigma-Aldrich Corp., St. Louis, MO), 7-ethoxy-4-(trifluoromethyl)-coumarin (EFC, $30 \mu \mathrm{M}$; Cyp2b; cat. no. T2803; Sigma-Aldrich Corp.), dibenzylfluorescein (DBF, $10 \mu \mathrm{M}$; Cyp2c; cat. no. 451740; Corning Inc.), 3-[2-( $N, N$-diethyl- $N$-methylammonium)ethyl]-7-methoxy4-methylcoumarin (AMMC, $100 \mu \mathrm{M}$; Cyp2d; cat. no. 451700; Corning Inc.), 7-methoxy-4-(trifluoromethyl)-coumarin (MFC, $10 \mu \mathrm{M}$; Cyp2e1; cat. no. 451740; Corning Inc.), or 7-benzyloxy-4-trifluoromethylcoumarin (BFC, $100 \mu \mathrm{M}$; Cyp3a; cat. no. B5057; Sigma-Aldrich Corp.) at time 0 hour. The media containing CEC metabolite 3-cyano-7hydroxycoumarin (CHC; cat. no. 451015; Corning Inc.), CM metabolite 7-hydroxycoumarin (7-HC; cat. no. H24003; Sigma-Aldrich Corp.), BFC, EFC, and MFC metabolite 7-hydroxy-4-trifluoromethylcoumarin (HFC; cat. no. 451731; Corning Inc.), or DBF metabolite fluorescein (cat. no. 46955; Sigma-Aldrich Corp.), along with their glucuronide and sulfate conjugates formed during the assay were collected at defined time points. The AMMC metabolite AMHC was commercially unavailable, and thus 3-[2-(diethylamino)ethyl]-7-hydroxy-4-methylcoumarin (AHMC; cat. no. 188611; Sigma-Aldrich Corp.) was used instead as previously described for the fluorescence quantification (Donato et al., 2004). The conjugates were hydrolyzed by incubation of the media with glucuronidase/arylsulfatase (150 Fishman units/ml and 1200 Roy units/ml, respectively) for 2 hours at $37^{\circ} \mathrm{C}$. The medium concentrations of $\mathrm{CEC}, 7-\mathrm{HC}, \mathrm{HFC}$, fluorescein, and AHMC were fluorometrically monitored at the wavelength [excitation (nanometer)/emission (nanometer)] of 408/455, 355/460, 
A
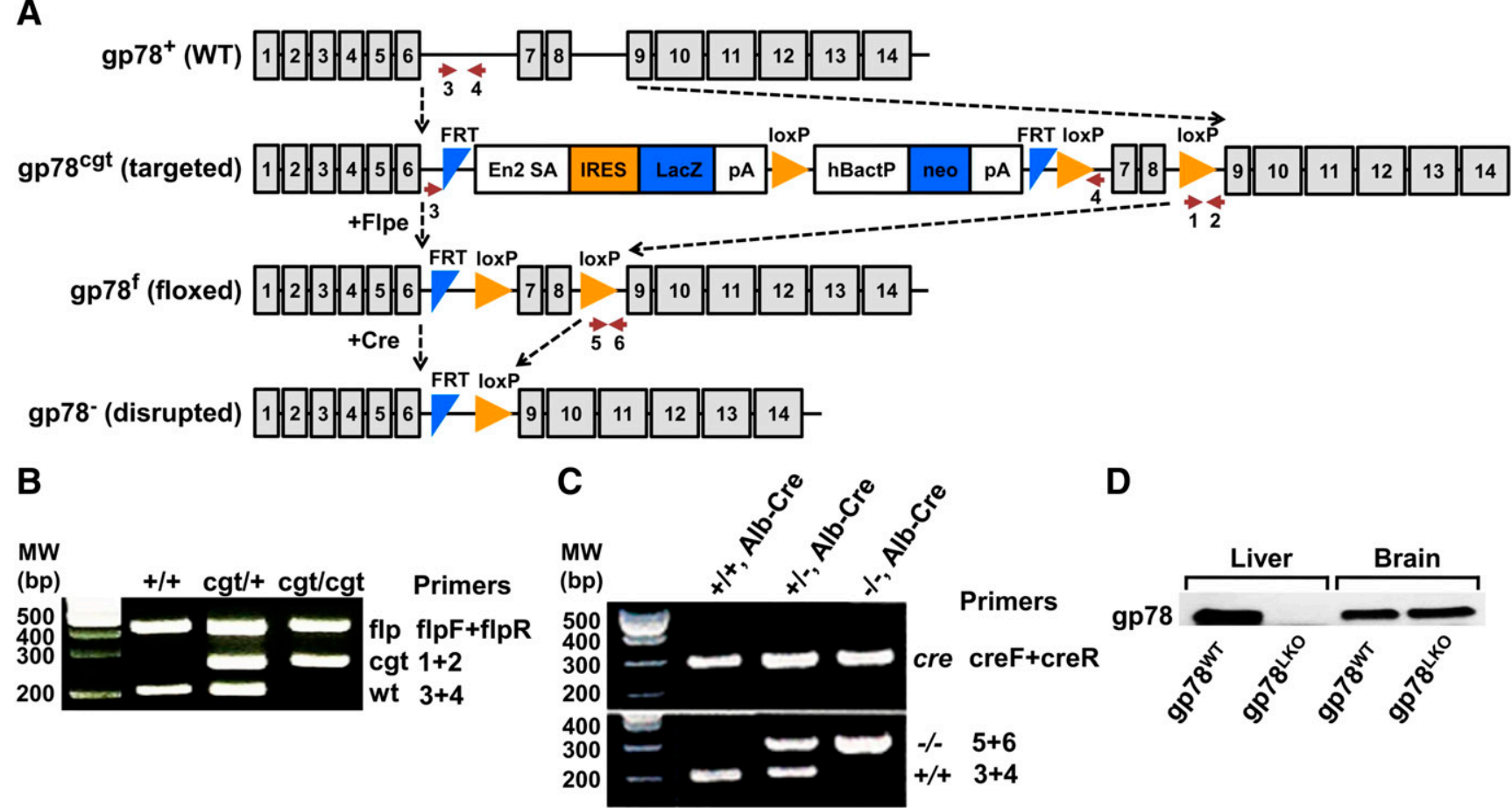

D

Fig. 1. Strategy for generating the liver-conditional gp78/AMFR-KO mouse model and corresponding validation. (A) Conditional gene trap (cgt) strategy to develop gp78-floxed $\left(\mathrm{gp} 78^{\mathrm{f}}\right)$ mice and, subsequently, liver-conditional gp78-KO mice $\left(\mathrm{gp} 78^{-}\right)$. Arrows indicate the sites of the genotyping primers employed. (B and C) PCR genotype analyses of genomic DNA isolated via tail-clipping of mice at various stages of the strategy. See Materials and Methods for experimental details. The primer pairs for each genotyping product and the corresponding amplicon size are indicated. flpF/flpR primers used to verify the amplicon obtained upon Flpe recombinase in WT $(+/+)$; cgt/+, heterozygous with the cgt-cassette insert; and cgt/cgt, homozygous with the cgtcassette insert. Amplicons verifying WT gp78 (+/+), Alb/Cre, heterozygous gp78-KO (+/-), and Alb-Cre and homozygous gp78-KO (-/-), each Alb-Cre carrying an Alb-Cre allele upon mating with Alb-Cre/Alb-Cre mice. (D) IB analyses of liver and brain lysates from WT and KO mice with a rabbit antimouse gp78-antibody, verifying the liver-specific gp78 KO.

410/510, 485/538, and 390/460, respectively, using the commercially purchased metabolites as authentic standards.

Nicotine Metabolism in Cultured Mouse Hepatocytes. WT and gp78-KO hepatocytes were PB-pretreated as described above. On day 4, (-)-nicotine (500 $\mu \mathrm{M})$ was added at time 0 hour and the cells and media were collected at $2,4,8$, and 24 hours, and incubated with glucuronidase/arylsulfatase for 2 hours at $37^{\circ} \mathrm{C}$. The reaction was stopped by the addition of ice-cold $30 \%$ perchloric acid, and the precipitated proteins were sedimented by centrifugation $(15,000 \mathrm{~g}$, 10 minutes, $4^{\circ} \mathrm{C}$ ). Nicotine metabolites (cotinine and trans-3'-hydroxycotinine, nornicotine, norcotinine, nicotine- $N$-oxide, and cotinine- $N$ oxide) were extracted from the supernatant and quantified by liquid chromatography-tandem mass spectrometry (LC-MS/MS) analyses as described for cotinine and trans-3'-hydroxycotinine (Jacob et al., 2011), with minor modifications for the additional analytes (Benowitz et al., 2010, Wang et al., 2018a). The metabolites were found largely in the media, with relatively much smaller levels detected in the cell lysates.
Tamoxifen Metabolism in Cultured Mouse Hepatocytes. Cyp3a was induced by DEX-pretreatment of primary hepatocytes as described above. On day 4, cultured hepatocytes were treated with tamoxifen $(40 \mu \mathrm{M})$ for 2,4 , and 8 hours. The concentrations of tamoxifen and its metabolites, 4-hydroxytamoxifen, $N$-desmethyltamoxifen, and endoxifen, in the media were determined using a high-performance liquid chromatography-mass spectrometric (HPLC-MS) assay (Dahmane et al., 2010; Binkhorst et al., 2011). Toremifen was employed as an internal standard, and spiked into the media at $1 \mu \mathrm{M}$. The medium was incubated with glucuronidase/arylsulfatase for 2 hours at $37^{\circ} \mathrm{C}$ and the reactions terminated by the addition of $2 \times$ volume of ice-cold acetonitrile containing $0.1 \%$ formic acid. Precipitated proteins were removed by sedimentation at $10,000 \mathrm{~g}$ for 10 minutes at $4^{\circ} \mathrm{C}$, and an aliquot $(300 \mu \mathrm{l})$ of the supernatant was mixed with $50 \mathrm{mM}$ glycine buffer ( $\mathrm{pH} 11.5 ; 700 \mu \mathrm{l})$. An aliquot $(50 \mu \mathrm{l})$ of this mixture was injected into the HPLC system (Waters Separation Module 2695; Waters Corporation, Milford, MA), equipped with a C18 reversed-phase column $(100 \times 2.1 \mathrm{~mm}, 3 \mu \mathrm{m}$, Hypersil Gold

TABLE 3

Primers used for qRT-PCR analyses of P450 mRNA expression

\begin{tabular}{ll}
\hline Gene & \multicolumn{1}{c}{ Sequence $5^{\prime} \rightarrow 3^{\prime}$} \\
\hline Cyp $1 a 2$ & ATGATGAGAAGCAGTGGAAAGA CAGGATGGCTAAGAAGAGGAAG \\
Cyp2a5 & CACCCAGATATTGAGGCCAA CCCAGCATAGGAAACACTTCA \\
Cyp $2 b 10$ & AGGAGGAAGCCCAATGTTTAG CTCAAACATCTGGCTGGAGAA \\
Cyp $2 c 29$ & GTCACAGCTAAAGTCCAGGAAG TCATGCAGCACTGATGACAG \\
Cyp 2 c 39 & GCAGGTCTGCAATAATTTCCC GTTGGATGTGATTTGCCTGTT \\
Cyp $2 d 10$ & CTGGCAGAGATAGAGAAGGTAAAG CCCTATGACCGCATCGATTT \\
Cyp $2 e 1$ & TCCTCATAGAGATGGAGAAGGAAA GGCCCAATAACCCTGTCAAT \\
Cyp3a 11 & GTGAACGTGGATTCCCTCAA CTCGGTGCTTCTGCTTAGAAT \\
Cyp $3 a 13$ & TACCCTGCTACAGATGGAGTAT CTGATTCTTCTTGCTGAACCTTTC \\
gapdh & ACCACAGTCCATGCCATCAC CACCACCCTGTTGCTGTAGCC \\
\hline
\end{tabular}


aQ; Thermo Fisher Scientific), and maintained at a temperature of $30^{\circ} \mathrm{C}$. An aqueous solution containing $0.1 \%$ formic acid was used as the mobile phase $\mathrm{A}$, and acetonitrile containing $0.1 \%$ formic acid was used as the mobile phase B. Mobile phases A (30\%) and B $(70 \%)$ were applied isocratically at a flow rate of $0.2 \mathrm{ml} / \mathrm{min}$. The peaks were detected at $254 \mathrm{~nm}$ by Waters dual absorbance detector 2487 (Waters Corporation). The retention times of endoxifen, 4-hydroxytamoxifen, toremifen, $N$-desmethyltamoxifen, and tamoxifen were 9.26, 11.16, 22.17, 23.77, and 26.92 minutes, respectively. The HPLC system was connected to a Waters Micromass ZQ single quadrupole mass analyzer (Waters Micromass Corporation, Manchester, U.K.), equipped with an electrospray ionization probe operated in the positive ionization mode. The ionspray and cone voltage were $3 \mathrm{kV}$ and $45 \mathrm{~V}$, respectively. The protonated molecular ion $[\mathrm{M}+\mathrm{H}]^{+}$masses of $N$-desmethyltamoxifen, tamoxifen, endoxifen, 4-hydroxytamoxifen, and toremifen were found to be 358.2, 372.2, 374.2, 388.2, and $406.2 \mathrm{amu}$, respectively.

Chlorzoxazone Metabolism in Cultured Mouse Hepatocytes. Cultured primary WT and KO mouse hepatocytes were INHpretreated to induce Cyp2e1, as described above. On day 4, at time 0 hour, chlorzoxazone $(400 \mu \mathrm{M})$ was added to the hepatocytes for 3 hours. The 6-hydroxychlorzoxazone (6-OH CZX) formed by Cyp2e1 was monitored by HPLC as described (Girre et al., 1994) with a slight modification. The collected medium was first incubated with glucuronidase/arylsulfatase for 2 hours at $37^{\circ} \mathrm{C}$, and the reaction stopped with $40 \%$ perchloric acid. After sedimentation of the precipitated protein, the supernatant was mixed with $1.5 \times$ volume of ethyl acetate by vigorous vortex mixing for 20 minutes. The upper organic phase was collected and evaporated at $40^{\circ} \mathrm{C}$. The resulting residue was reconstituted with $100 \mu \mathrm{l}$ of mobile phase, acetonitrile, and $0.5 \%$ acetic acid $(30: 70, \mathrm{v} / \mathrm{v}, \mathrm{pH} 3)$, and a $50-\mu \mathrm{l}$ aliquot was injected into a Varian Prostar HPLC (Varian Inc., Palo Alto, CA) system, equipped with a Grace Prosphere $100 \mathrm{C} 18,5 \mu \mathrm{m}$, 4.6- $\times 150-\mathrm{mm}$ column (Thermo Fisher Scientific) for metabolite separation at a flow rate of $1.1 \mathrm{ml} / \mathrm{min}$. of $6-\mathrm{OH}-\mathrm{CZX}$ (retention time of 7.6 minutes) was detected at $287 \mathrm{~nm}$ with a Varian Prostar 335 UV detector (Varian Inc.).

Acetaminophen-Induced Hepatotoxicity. Cultured mouse hepatocytes pretreated with INH $(1 \mathrm{mM})$ for 3 days were used for the acetaminophen (APAP) toxicity assay. On day 4, hepatocytes were incubated with APAP $(1$ or $5 \mathrm{mM})$ and the medium was collected at 2 , 4,8 , and 24 hours. The medium alanine aminotransferase (ALT) activity was quantified using the ALT assay kit (MAK052; SigmaAldrich Corp.).

In Vivo APAP-Induced Hepatotoxicity in Liver-Specific gp78-KO Mice. Male 8 week-old C57BL/6 mice (WT, $n=5$; gp78 $\mathrm{KO}, n=5$ ) were fasted overnight (12 hours). APAP ( $200 \mathrm{mg} / \mathrm{kg}$, i.p.) dissolved in $0.9 \% \mathrm{NaCl}$ solution $(10 \mathrm{ml} / \mathrm{kg}$ ) was injected into the mice at time 0 hour. Blood was collected from the facial vein at 0,6 , and 12 hours after the injection, and the mice were killed at 12 hours to collect the liver tissue. Serum was isolated from the whole blood and ALT levels were monitored as described above. Hepatic malondialdehyde (MDA) levels were measured using liver homogenates by the TBARS assay kit (cat. no. 10009055; Cayman Chemical, Ann Arbor, MI). Cyp2e1 and Cyp3a protein levels in liver homogenate ( $5 \mu \mathrm{g})$ were determined by Western IB analyses using corresponding antibodies as indicated above. Fresh liver tissues were stored in $10 \%$ neutral buffered formalin, and the tissue sections were stained with hematoxylin and eosin. Microscopic histopathologic examination was performed by the UCSF Liver Center Pathology, Histology and Light Microscopy Cores.

Statistical Analyses. In a strict statistical sense, this study is exploratory by nature and accordingly, all statistical analyses, employing the Student's $t$ test, should be considered descriptive and not hypothesis-testing. Our sample size was planned to be at least three male mice, but final sample sizes depended on how many male mice were in a given litter.

\section{Results}

\section{Verification of the Liver-Conditional gp78-KO Mouse Genotype}

The cgt-targeting strategy employed is shown (Fig. 1A). This strategy is different from that reported previously (Liu et al., 2012) in that the cgt cassette targeted only seven to eight exons (vs. five to eight), and it also employed resuscitated cryopreserved embryos rather than genetically engineered embryonic stem cells as the starting material. Verification of the genomic DNA by tail-clip genotyping via PCR analyses of wild-type (WT; gp $78^{+/+}$) flp/flp-mice, cgt/+, gp $78^{+/-}$, and gp $78^{-/-}$mice, respectively, is shown (Fig. 1, B and C). Parallel IB analyses of liver and brain tissue lysates from WT and gp $78^{-1-}$-mice provided unequivocal evidence of liver-conditional gp78 KO (Fig. 1D).

\section{Identification of Hepatic P450s as gp78 Targets}

IB analyses of lysates from untreated, freshly isolated hepatocytes revealed the statistically significant stabilization of constitutive Cyp2e1 and Cyps 3a upon liver-conditional gp78 KO relative to corresponding age/strain-matched WT mice (Fig. 2). A slight, albeit statistically significant relative stabilization of constitutive Cyps 2c was also likewise detected (Fig. 2). By contrast, the expression of constitutive Cyps 2a, for reasons currently unclear, was statistically significantly decreased upon gp78 KO (Fig. 2). Furthermore, consistent with our gp78-shRNAi findings in cultured rat hepatocytes, IB analyses of lysates from cultured mouse hepatocytes verified that DEX-inducible Cyps 3a and INH-inducible Cyp2e1 were also statistically significantly stabilized upon gp78 KO $\left(\mathrm{gp} 78^{-/-}\right.$) relative to those in the WT (Fig. 3). Corresponding diagnostic functional probes revealed that this stabilization was largely of the functionally active forms (Fig. 4). Similar conclusions were also drawn for PB-inducible Cyps 2c (Figs. 3 and 4). The Cyp1a2 increase in gp $78^{-/-}$hepatocytes relative to the WT hepatocytes, on the other hand, may be partially attributable to transcriptional induction (Fig. 5). By contrast, the relative hepatic content and corresponding functional activity of Cyps 2d were unaffected, whereas those of Cyps $2 \mathrm{~b}$ were even decreased upon gp78 KO (Figs. 3 and 4). Surprisingly, in contrast to the statistically significant reduction of constitutive Cyps 2 a (Fig. 2), a marked stabilization of PB-inducible Cyps 2 a was observed in gp $78^{-/-}$over gp $78^{+/+}$ hepatocytes (Fig. 3), with a correspondingly marked relative increase of coumarin-7-hydroxylase in gp $78^{-/-}$over gp $78^{+/+}$ hepatocytes (Fig. 4). Thus, in addition to Cyps 3a and Cyp2e1, these studies identified Cyps 2a and Cyps 2c as gp78 targets, with their diagnostic functional probes attesting to their corresponding statistically significant functional increases. Furthermore, on the basis of: 1) the observed PB inducibility of the Cyp2a enzyme; 2) its close functional correlation with the elevated coumarin-7-hydroxylase activity, an excellent Cyp2a5 but not Cyp2a4-diagnostic probe (Chang and Waxman, 1996), coupled with 3 ) its ability for cotinine and trans-3'-hydroxycotinine formation (see below; Zhou et al., 2010), lead us to propose Cyp2a5 as the Cyp2a isoform most probably stabilized.

Functional P450 Enhancement Results from Corresponding P450 Protein Stabilization upon gp78 KO. We have previously reported that the CYP3A stabilization upon lentiviral shRNAi-elicited gp78 knockdown in cultured rat hepatocytes is attributable to its protein stabilization rather than increased CYP3A mRNA expression (Kim et al., 

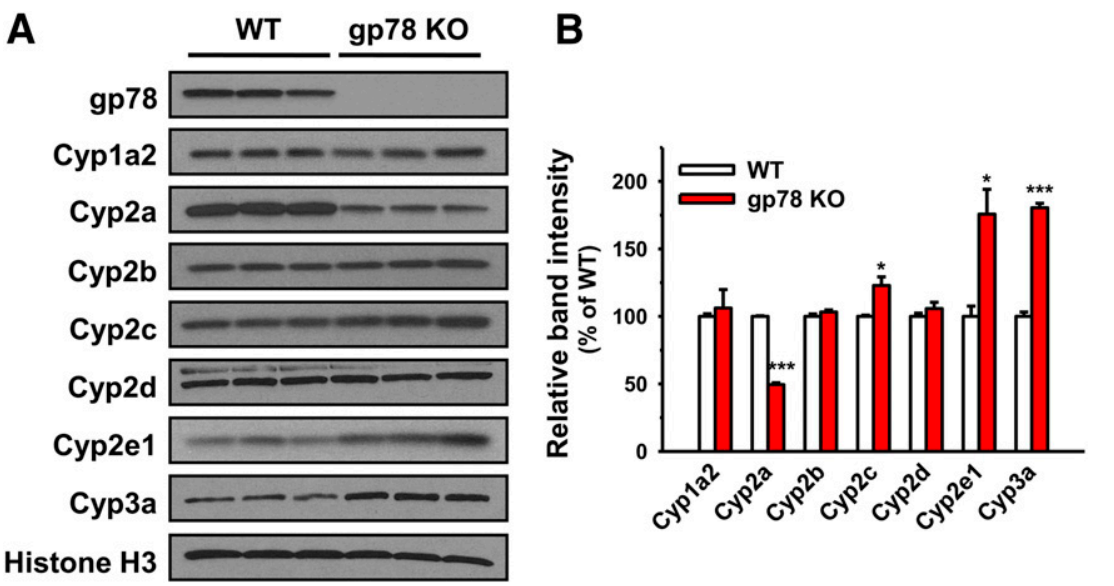

Fig. 2. IB analyses of constitutive hepatic P450s from WT and gp78-KO mice. (A) IB analyses of a representative mouse sample. (B) Densitometric quantification of the approx. 50-55 kDa P450 band from hepatocytes freshly isolated and uncultured from three individual WT and gp78-KO mice. See Materials and Methods for details. Values (mean \pm S.D.) of three individual experiments, each employing two culture plates (technical replicates) of hepatocytes isolated from each of the three mice. Statistical significance determined by the Student's $t$ test, ${ }^{* * * * * *} P<0.05$, and 0.001 vs. WT, respectively.

2010). Relative hepatic P450 mRNA expression analyses by qRT-PCR analyses of total RNA isolated from $\mathrm{gp}^{-1-}$ and gp $78^{+/+}$hepatocytes after each $\mathrm{P} 450$-inducer pretreatment coupled with the use of $\mathrm{P} 450$ isoform-specific probes revealed that the observed relative $\mathrm{P} 450$ content and functional increases (except in the case of Cyp1a2) were not caused by their transcriptional mRNA induction (Fig. 5).

Cycloheximide-chase analyses of gp $78^{-/-}$and gp $78^{+/+}$hepatocytes coupled with concurrent treatment with either the proteasome inhibitor bortezomib or the ALD inhibitors (3-MA/ $\mathrm{NH}_{4} \mathrm{Cl}$ ) revealed that Cyp2a5 degradation was considerably slower in $\mathrm{gp} 78^{-/-}$hepatocytes relative to gp $78^{+/+}$hepatocytes but involved both UPD and ALD (Fig. 6A). Cyp2a5 immunoprecipitation from PB-pretreated gp $78^{-/-}$and gp $78^{+/+}$hepatocytes and protein ubiquitination analyses directly verified that Cyp2a5 was primarily a gp78 target, as its ubiquitinated level was markedly reduced upon gp78 KO, and bortezomibmediated inhibition of its proteasomal degradation failed to enhance it (Fig. 6B). Thus, gp78-mediated Cyp2a5 ubiquitination targets the protein for both UPD and ALD.

\section{Pharmacological Relevance of Hepatic P450 Stabilization upon gp78 KO}

With the exception of coumarin, the above functional analyses employed readily assayable fluorescent diagnostic probes rather than therapeutic and/or pharmacologically active drugs as substrates. To determine the potential therapeutic relevance of CYP2e1 stabilization upon gp78 KO, we examined in gp78 ${ }^{-/-}$and gp $78^{+/+}$hepatocytes the Cyp2e1dependent 6-hydroxylation of chlorzoxazone, a clinically prescribed skeletal muscle relaxant and an established Cyp2e1 functional probe, (Fig. 7A). A statistically significant relative increase was detected in 6-OH-chlorzoxazone formation in gp $78^{-/-}$over gp $78^{+/+}$hepatocytes (Fig. 7A), comparable to that observed with its other diagnostic Cyp2e1 probe (MFC) (Fig. 4), thus underscoring the potential therapeutic significance of these findings.

Cyp2e1 largely and Cyps 3a to a lesser extent are also involved in the metabolism of the clinically prescribed nonsteroidal analgesic acetaminophen (APAP) to its reactive nucleophilic species $N$-acetylparaquinoneimine (NAPQI) (Lee et al., 1996; Wolf et al., 2007). This pathway becomes increasingly hepatotoxigenic when liver concentrations of ingested APAP exceed the detoxification capability of its hepatic glucuronidation and sulfation pathways (Gillette et al., 1981; Nelson, 1990). More of the parent drug is then shunted into the reactive NAPQI pathway with consequent liver damage that can be clinically fatal (Nelson, 1990). To determine the potentially hepatotoxicological relevance of Cyp2e1 functional stabilization upon gp78 KO, we examined INH-pretreated gp $78^{-1-}$ and gp $78^{+/+}$hepatocytes treated with APAP at two different concentrations: $5 \mathrm{mM}$, the concentration routinely employed to trigger APAP-induced

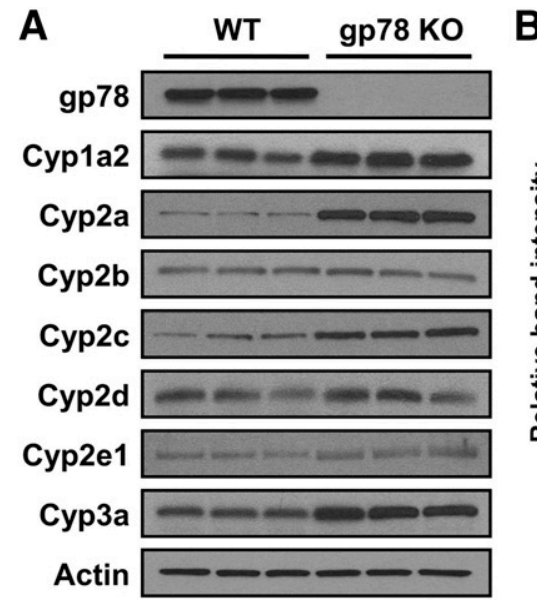

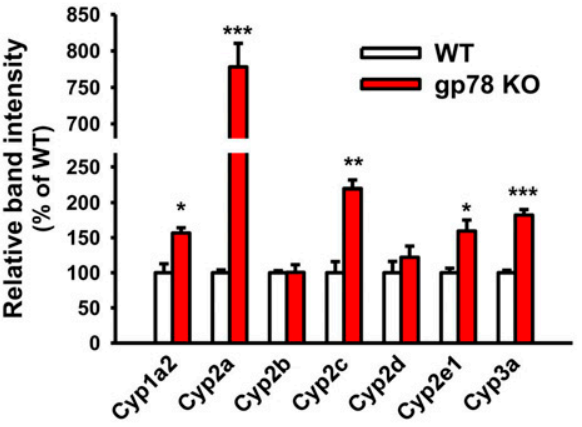

Fig. 3. IB analyses of hepatic P450s from cultured WT and gp78-KO mouse hepatocytes. (A) IB analyses of a representative mouse sample. (B) Densitometric quantification of the approx. 50- to $55-\mathrm{kDa} \mathrm{P} 450$ band from hepatocytes isolated from three individual WT and gp78-KO mice, cultured and pretreated with P450inducers. See Materials and Methods for details. Values (mean \pm S.D.) of three individual experiments, each employing two culture plates (technical replicates) of hepatocytes isolated from each of the three mice. Statistical significance determined by the Student's $t$ test, ${ }^{*, * *, * * * *} P<0.05,0.01$, and 0.001 vs. WT, respectively. 

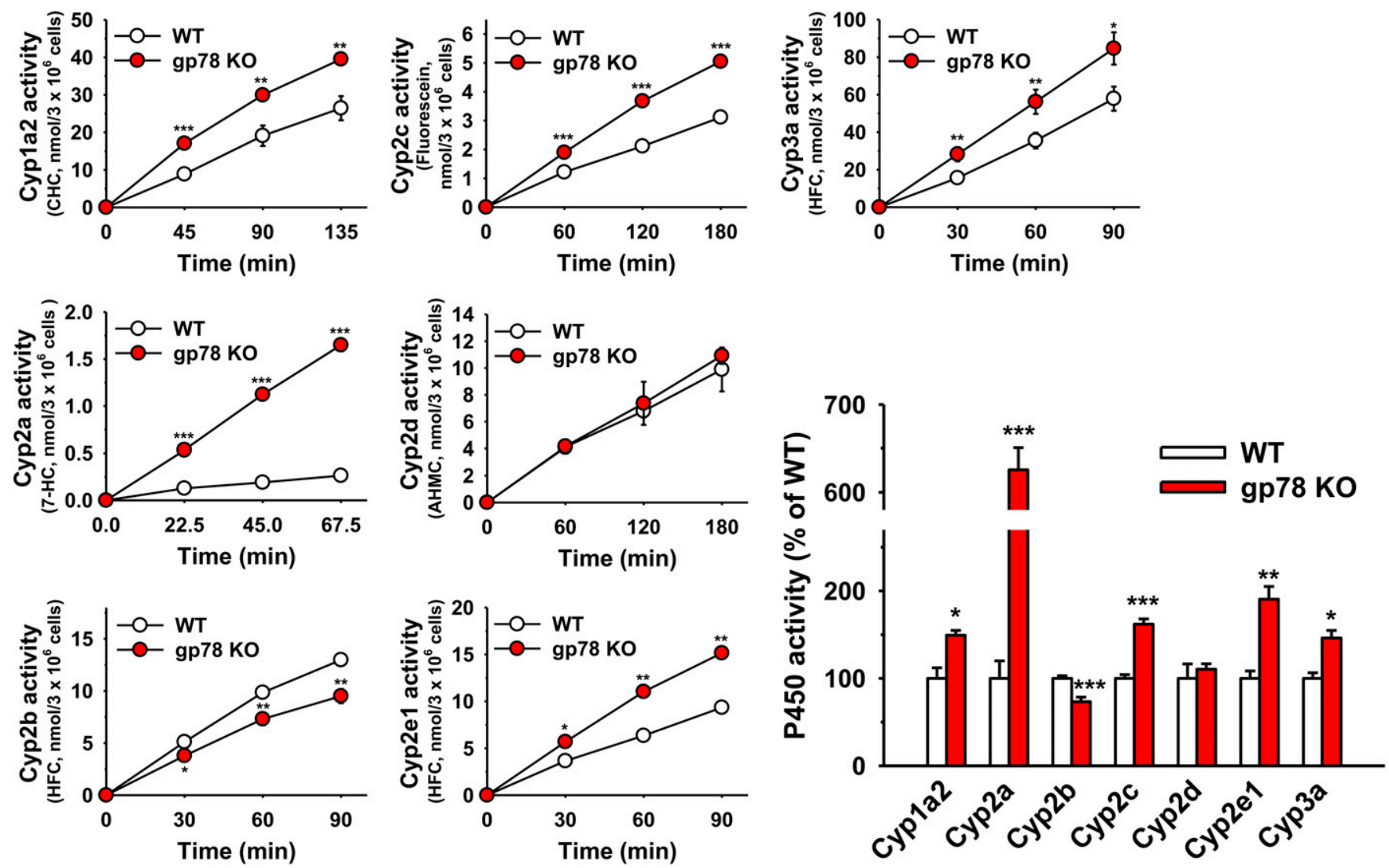

Fig. 4. P450 functional screening using diagnostic fluorescent probes. Hepatocytes from three WT and gp78-KO mice were cultured separately, pretreated with P450-inducers, and then incubated with individual diagnostic functional probes at time 0 hour. See Materials and Methods for details. Values (mean \pm S.D.) of three individual experiments each employing two culture plates (technical replicates) of hepatocytes isolated from each of the three mice. Statistical significance determined by the Student's $t$ test, $* * * * * * P<0.05,0.01$, and 0.001 vs. WT, respectively.

liver damage (Burcham and Harman, 1991; Bajt et al., 2004), and $1 \mathrm{mM}$, one-fifth the toxic concentration, over 24 hours of culture. Although, as expected, the $5-\mathrm{mM}$ concentration led to statistically significantly increased injury to gp $78^{+/+}$hepatocytes, as monitored by the extracellular spillage into the cell medium of the liver cytoplasm-specific ALT enzyme, this was statistically significantly greater in $\mathrm{gp} 78^{-1-}$ hepatocytes (Fig. 7B). At the 1-mM concentration, however, although APAP produced a mild extracellular ALT rise in gp $78^{+/+}$ hepatocytes, this was considerably accelerated and pronouncedly greater in gp $78^{-/-}$hepatocytes (Fig. 7B). These findings thus attest to the relevance of $\mathrm{P} 450$ stabilization upon gp78 KO to drugs whose hepatotoxigenic potential largely depends on their Cyp2e1-mediated bioactivation.

Furthermore, to determine the pharmacological relevance of the relatively marked functional Cyp2a5-stabilization, we also determined its effects on the metabolism of its prototype drug substrate nicotine, a pharmacologically active drug (Fig. 8). As expected, nicotine was metabolized to cotinine (via the nicotine-iminium ion and subsequent oxidation by aldehyde oxidase), nornicotine, norcotinine, trans-3'-hydroxycotinine, nicotine- $N$-oxide, and cotinine- $N$-oxide (Cashman et al., 1992; Nakajima et al., 1996; Hukkanen et al., 2005; Siu et al., 2006; Zhou et al., 2010). Whereas the nicotine- $N$-oxide is reportedly generated by flavin-monooxygenase (FMO3; Cashman et al., 1992), the other four metabolites are generated by various $\mathrm{P} 450 \mathrm{~s}$, of which Cyp2a5 is the major catalyst (Nakajima et al., 1996; Siu et al., 2006; Zhou et al., 2010). On the other hand, trans-3'-hydroxycotinine is selectively generated by CYP2A6, a Cyp2a5 ortholog (Nakajima et al., 1996; Siu et al., 2006; Zhou et al., 2010). Our results revealed that, indeed, from 2 hours onwards, consistent with the marked increase in Cyp2a5, there is a statistically significant, accelerated increase in cotinine formation, with a 2 -fold increase in trans-3'-hydroxycotinine formation detected at 24 hours in gp78 ${ }^{-/-}$over gp $78^{+/+}$hepatocytes (Fig. 8) - thus, not quite as high as the marked functional fold-increases observed with the diagnostic Cyp2a5 functional marker (coumarin) (Fig. 4) but statistically significant nonetheless. One issue with monitoring secondary drug metabolism in isolated cultured hepatocytes in general is that the primary metabolite (cotinine) spills out into the cell medium almost as quickly as it is generated, thus not allowing sufficient time for its subsequent Cyp2a5-selective trans-3'-hydroxycotinine conversion. Thus, only when sufficient cotinine accumulates intracellularly with time (24 hours) is the trans-3'-hydroxycotinine conversion detectable (Fig. 8). This is also true of the other P450dependent cotinine metabolites, whose relative increases were maximally detected at 24 hours. By contrast, the FMO3 metabolite nicotine- $N$-oxide was decreased, rather than increased, in gp $78^{-1-}$ hepatocytes, thereby revealing that FMO3 was, if at all, decreased rather than increased upon gp78 KO. The other issue is that nicotine itself may incur enhanced substrate competition by other P450s that not only are known to metabolize it (Zhou et al., 2010) but are also increased upon gp78 KO, which is not the case with the 


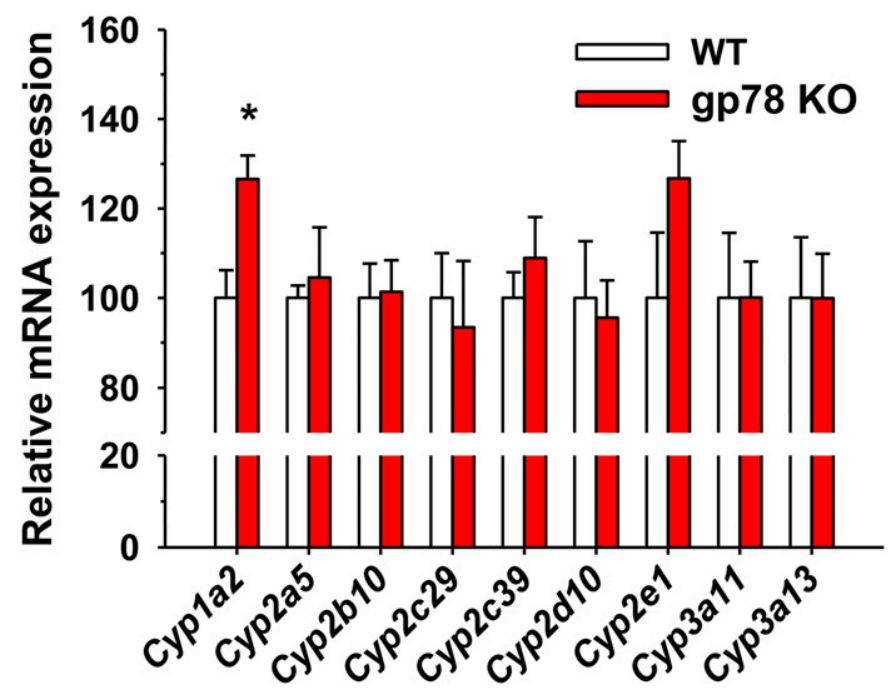

Fig. 5. Relative P450 mRNA expression in cultured WT and gp78-KO mouse hepatocytes. Total RNA was extracted on day 4 from cultured hepatocytes, untreated or pretreated with $\mathrm{P} 450$ inducers for 3 days. Hepatic P450 mRNA expression was determined by qRT-PCR analyses as detailed in Materials and Methods. Values (mean \pm S.D.) are derived from three individual cultures pretreated with P450 inducers as detailed. Statistical significance determined by the Student's $t$ test, ${ }^{*} P<0.05$ vs. WT. GAPDH mRNA Ct levels (mean \pm S.D.) between P450-inducer pretreated WT and gp78-KO cultured hepatocytes were as follows: $\beta \mathrm{NF}$ : $100 \pm 1.92(\mathrm{WT}) / 101.49 \pm 1.75(\mathrm{gp} 78 \mathrm{KO}) ; \mathrm{PB}: 100 \pm 1.67(\mathrm{WT}) / 100.33 \pm$ 1.61 (gp78 KO); INH: $100 \pm 1.99$ (WT)/99.72 \pm 1.66 (gp78 KO); DEX: $100 \pm$ 2.19 (WT)/102.85 \pm 3.94 (gp78 KO). No statistically significant differences were noted by the Student's $t$ test in GAPDH Ct values between WT and gp78-KO cultured hepatocytes pretreated with each of the four P450 inducers. $\mathrm{Ct}$, threshold cycle.

relatively more selective Cyp2a5 diagnostic probe. Nevertheless, these findings indicate that gp78 $\mathrm{KO}$ can statistically significantly increase the metabolism of pharmacologically active drugs by enhancing hepatic Cyp2a5 levels through protein stabilization.

Pharmacologically relevant drugs often involve multiple hepatic P450s, each catalyzing a different step of their biotransformation pathway. Such biotransformation is relevant not only to their elimination, DDIs, and toxicity but also often to their pharmacological response through prodrug metabolic bioactivation. We therefore sought to determine the relevance of gp78 $\mathrm{KO}$ to the bioactivation of the estrogen receptor-positive breast cancer therapeutic prodrug tamoxifen. Tamoxifen bioactivation involves two concurrent alternate sequential metabolic routes (Fig. 9; Jacolot et al., 1991; Desta et al., 2004; Goetz et al., 2007): It can be first converted to 4-hydroxytamoxifen by Cyp2d, which is then $\mathrm{N}$-demethylated by Cyps $3 \mathrm{a}$ to generate endoxifen. Alternatively, it could be first $\mathrm{N}$-demethylated by Cyps $3 \mathrm{a}$ to $N$-desmethyltamoxifen, which is then 4-hydroxylated by Cyp2d to generate endoxifen (Jacolot et al., 1991; Desta et al., 2004). Both routes thus generate endoxifen, the ultimately desired bioactive chemotherapeutic entity. Our findings reveal that upon gp78 $\mathrm{KO}$, although the Cyp2ddependent 4-hydroxylation step remains unchanged, consistent with unaltered hepatic Cyp2d levels, the bioactivation of tamoxifen to endotoxifen is nevertheless statistically significantly increased consistent with functional Cyp3a stabilization, and would be therapeutically relevant (Fig. 9).

\section{In Vivo Relevance of the P450 Stabilization}

Toxicological Implications. Our findings in cultured mouse hepatocytes upon genetic gp78 ablation, albeit providing proof of principle, may be equivocal and thus not entirely convincing of their plausible in vivo import. To specifically define their physiologic/toxicologic relevance in vivo, we employed the in vivo correlate of our APAPtreated cell culture model. Accordingly, male mice (8-weekold) treated with a mildly toxic APAP $(200 \mathrm{mg} / \mathrm{kg}$, i.p. $)$ dose at time 0 documented progressively increased serum ALT levels at 6 and 12 hours after treatment that were statistically significantly higher in gp78-KO mice than those in correspondingly treated WT mice (Fig. 10A). Concurrently, as in Fig. 2, hepatic Cyp2e1 and Cyp3a content in these mice, not treated with any $\mathrm{P} 450$ inducers, was statistically significantly elevated in gp78-KO relative to WT mice 12 hours post-APAP (Fig. 10, B and C). Correspondingly, the relative increases in hepatic MDA-levels (Fig. 10C), a reflection of Cyp2e1/Cyp3amediated enhanced APAP metabolism to the redox-active NAPQI species and consequent ROS generation, were also more pronounced in the gp78-KO than in WT mice. Although the APAP (200 mg/kg) dose administered was mildly toxic, characteristic APAP-elicited hepatic injury was observed in all gp78-KO and WT mice at 12 hours postadministration (Mitchell et al., 1973; McGill et al., 2013; Bhushan et al., 2014). More importantly, the severity of the hepatic centrizonal gross necrosis elicited by the mildly toxic APAP dose was considerably greater in the gp78 $\mathrm{KO}$ than in the correspondingly treated WT mice-with pyknotic nuclei, karyorrhexis, karyolysis, and cytoplasmic eosinophilia of the necrotic hepatocytes bridging adjacent lobules; polymorphonuclear cell infiltration; and the congestion of the hepatic sinusoidal spaces in the centrilobular and midzonal regions. Furthermore, judging by the perimeter of the polymorphonuclear cell infiltration "collar" of these coalesced necrotic lobules, this APAP-elicited hepatic necrosis was much more extensive in the gp78-KO than in the WT mice. Collectively, these findings not only underscore the therapeutic/hepatotoxicological relevance of hepatic Cyp2e1 and Cyp3a stabilization upon gp78 $\mathrm{KO}$ but also validate similar findings in cultured hepatocytes (Fig. 7B).

\section{Discussion}

We document herein for the first time that mouse hepatic Cyp2a5 and Cyps 2c, in addition to previously established Cyps $3 \mathrm{a}$ and Cyp2e1, are functionally stabilized upon liverconditional gp78/AMFR KO. Furthermore, we provide concrete novel evidence that Cyp2a5 not only is primarily a ubiquitination target of gp78 E3-ligase, but also, despite the preferential gp78 mode of K48-linked rather than K63linked ubiquitination ( $\mathrm{Li}$ et al., 2007), Cyp2a5 is targeted to both UPD and ALD. On the basis of our findings regarding their human CYP2C9 ortholog, Cyps 2c are quite probably also gp78-ubiquitination substrates (Kim et al., 2016b). Thus, the observed hepatic P450 stabilization upon disruption of their UPD through gp78 KO provides additional therapeutically relevant examples of eukaryotic protein induction via protein stabilization (Schimke and Doyle, 1970).

The mouse hepatic P450s stabilized upon gp78 KO have corresponding human orthologs that are involved not just in 
A
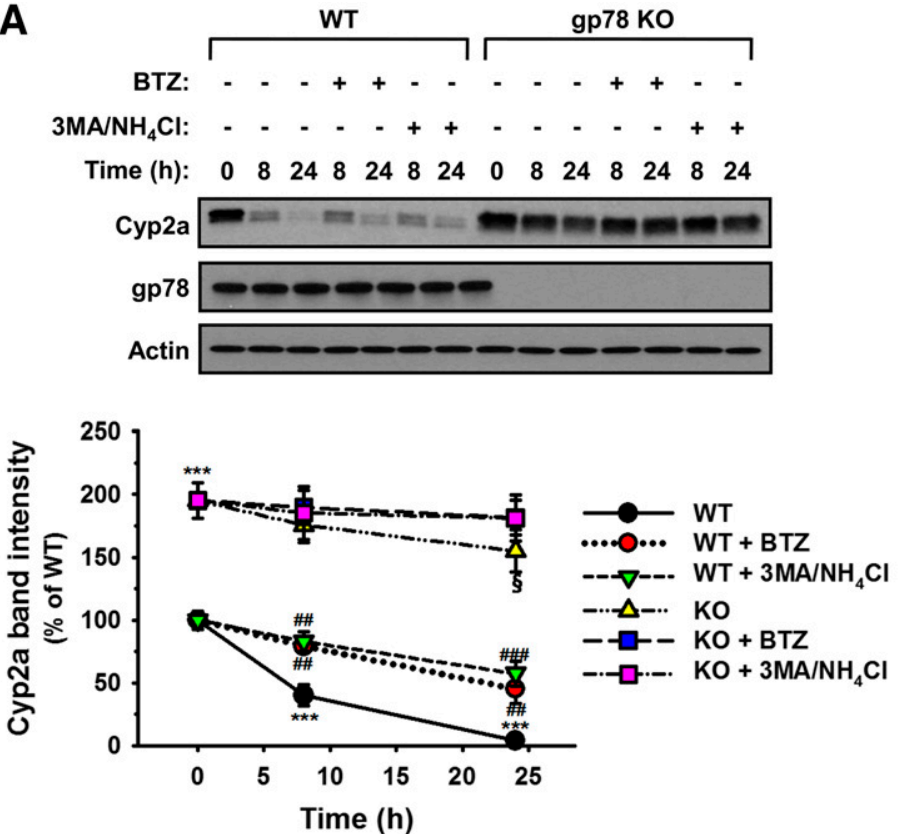

B

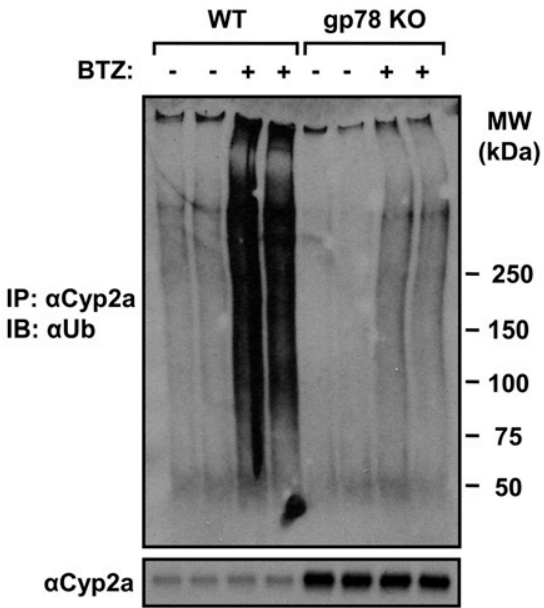

aCyp2a $--\pi-m-\infty=$

Fig. 6. Hepatic Cyp2a5 UPD and ALD: a major role of gp78 in Cyp2a5 ubiquitination. (A) Cycloheximide-chase analyses of hepatocytes from three individual WT and gp78-KO mice were cultured, PB-pretreated for 3 days, and on day 4 treated with or without the proteasomal inhibitor bortezomib (BTZ) or the ALD-inhibitors 3-MA/ $\mathrm{NH}_{4} \mathrm{Cl}$ for 0,8 , and 24 hours before cell harvesting. Cell lysates were immunoblotted for Cyp2a or gp78 with actin as a loading control. Densitometric quantification (mean \pm S.D.) of individual cultures from three mice. Statistical significance determined by the Student's $t$ test, ${ }^{* * *} P<0.001$ vs. WT at 0 hour; ${ }^{\# \#, \# \# \# P<0.01,0.001 \text { vs. WT }+C H X ; ~} \S P<0.05$ vs. KO at 0 hour. (B) Representative Ub-immunoblotting analyses of Cyp2a-immunoprecipitates from aliquots of PB-pretreated cultured cell lysates obtained from two of the three different mice treated with or without BTZ as in (A).

the metabolism and elimination of many clinically prescribed drugs, dietary agents, and environmental xenobiotics but also in their biotransformation either to more pharmacologically active or even more toxic/carcinogenic/mutagenic species (Guengerich, 2015; Correia, 2018). Employing pharmacological agents with therapeutic and/or hepatotoxigenic potential, we document herein that such hepatic P450 functional stabilization, if occurring in humans likewise, would be of clinical relevance. Accordingly, most therapeutic agents identified as specific substrates of a given hepatic P450 that is functionally stabilized upon gp78 KO would experience enhanced clearance and accelerated termination of their pharmacological action. Their therapeutic responses consequently would be curtailed, much akin to the impaired drug responses observed upon co-ingestion of therapeutic or dietary P450 inducers. For drugs such as nicotine, metabolized predominantly by human CYP2A6, its functional stabilization, while accelerating nicotine clearance, may also lead to enhanced nicotine craving in chronic cigarette smokers, and thus to an altered behavioral response. Moreover, given the major
A<smiles>O=c1[nH]c2cc(Cl)ccc2o1</smiles><smiles>O=c1[nH]c2cc(Cl)c(O)cc2o1</smiles>

Chlorzoxazone

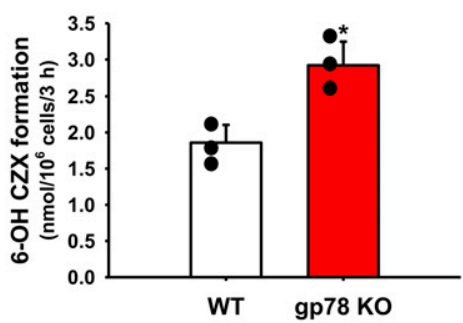

B<smiles>CC(=O)N=C1C=CC(=O)C=C1</smiles>

APAP

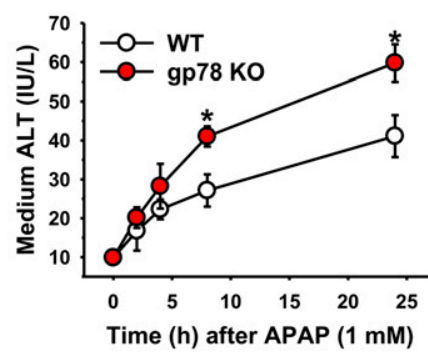

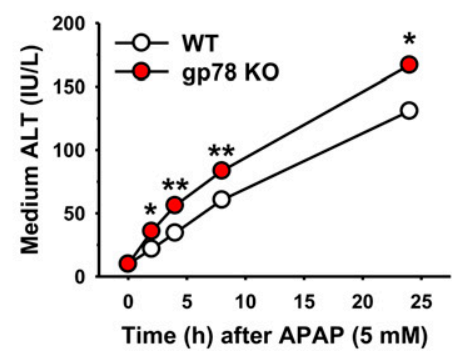

Fig. 7. Relative chlorzoxazone metabolism and APAP-elicited liver injury in cultured WT and gp78-KO mouse hepatocytes. (A) INH-pretreated hepatocytes (three individual cultures) from WT and gp78-KO mice were incubated on day 4 with chlorzoxazone for 3 hours and 6-hydroxychlorzoxazone assayed as detailed in Materials and Methods. Values (mean \pm S.D.) of three individual cultures. Statistical significance determined by the Student's $t$ test, ${ }^{*} P<0.05$ vs. WT. (B) WT and gp78-KO mouse hepatocyte cultures were INH-pretreated, and on day 4 incubated with APAP (1 or 5 mM) for $0-24$ hours. Aliquots of media were taken at the time points indicated and assayed for ALT activity as detailed in Materials and Methods. Values (mean \pm S.D.) of three individual cultures. Statistical significance determined by the Student's $t$ test, $* P<0.05$ vs. WT, $* * P<0.01$ vs. WT. 

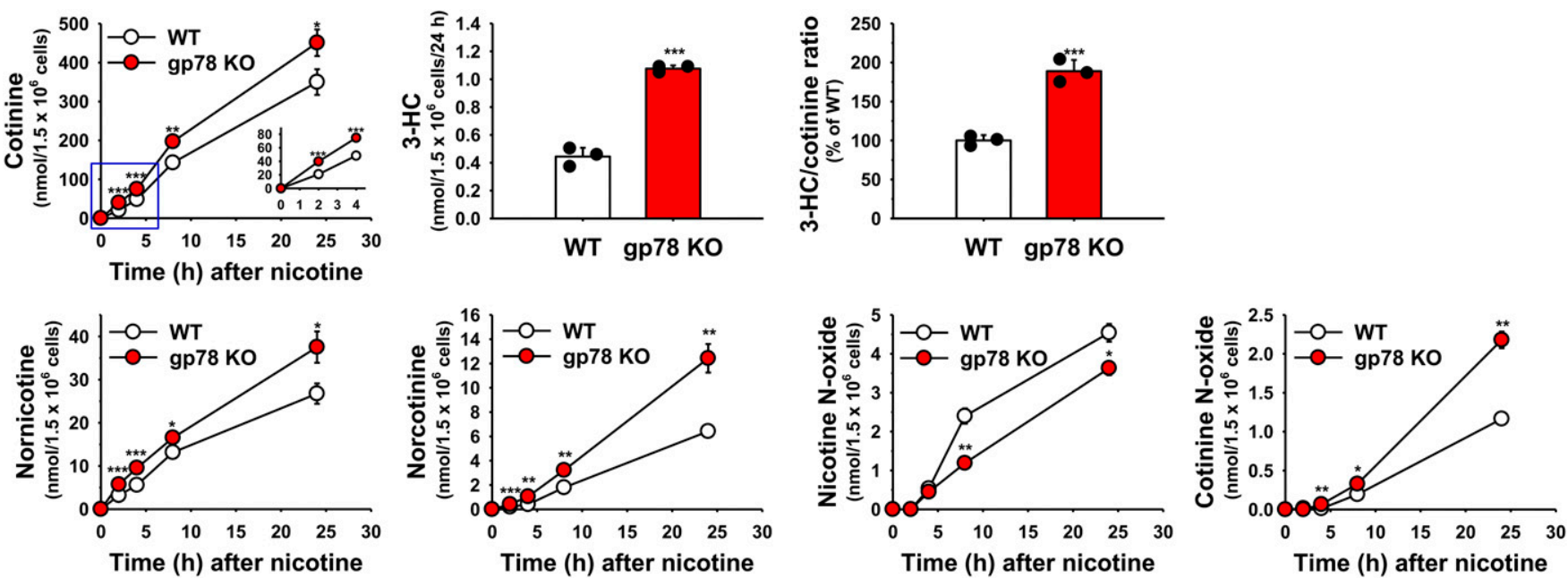

Fig. 8. Relative nicotine metabolism in cultured WT and gp78-KO mouse hepatocytes. PB-pretreated hepatocytes from WT and gp78-KO mice were cultured, and on day 4 incubated with nicotine for $0-24$ hours. Aliquots of media were taken at the time points indicated and assayed as detailed in Materials and Methods. The insert in the cotinine production graph is a magnified view of the initial three time points demarcated by the blue square. 3$\mathrm{HC}$ levels and $3-\mathrm{HC} /$ cotinine ratios were determined at 24 hour. Values (mean \pm S.D.) of three individual cultures. Statistical significance determined by the Student's $t$ test, $* P<0.05$ vs. WT, ${ }^{* *} P<0.01$ vs. WT, $* * * P<0.001$ vs. WT.

CYP2A6 role in the bioactivation of tobacco nitrosamines, including the tobacco-specific lung carcinogen 4-(methylnitrosamino)-1-(3-pyridyl)-1-butanone (NNK) and other toxic nitrosamines (Zhou et al., 2012; Zhu et al., 2013; Yuan et al., 2017), their carcinogenicity would also be enhanced.

Importantly, because many of these P450s are also involved in the metabolism of drugs (i.e., cancer chemotherapeutic agents) with narrow therapeutic indices, even minor oscillations in hepatic P450 content may translate into therapeutically undesirable losses of their pharmacological efficacy on the one hand, and toxicity on the other, as underscored previously (Peer et al., 2011) in support of the clinical relevance of our CHIP and gp78-shRNAi findings (Kim et al., 2010). Additionally, such enhanced hepatic $\mathrm{P} 450$ protein stability can also augment drug-elicited toxicity. Thus, the functional stabilization of hepatic Cyp2e1, and to a lesser extent that of Cyp3a, rendered the mildly toxic concentrations of APAP, a popular over-the-counter analgesic and a Cyp2e1/ Cyp3a substrate, statistically significantly more hepatotoxic to gp $78^{-1-}$ hepatocytes than to corresponding WT both in culture (Fig. 8) and live mice (Fig. 10). Although Cyp3a levels are low without concurrent Cyp3a induction in cultured INHpretreated gp78 ${ }^{-1-}$ hepatocytes, gp78 ablation would substantially synergize such toxicity in vivo owing to the
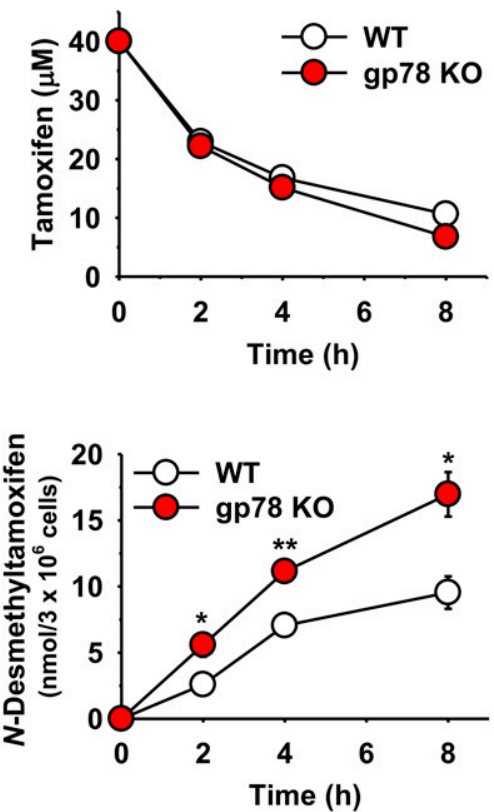

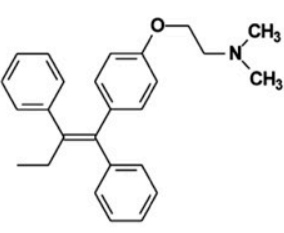

Tamoxifen Cур3a

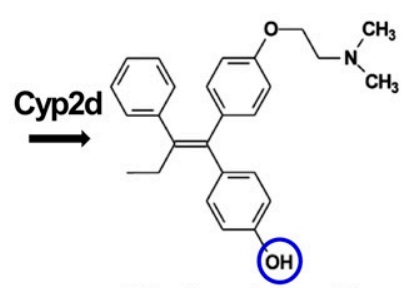

4-Hydroxytamoxifen Cур3a<smiles>CC/C(=C(\c1ccccc1)c1ccc(OCC[NH+](C)C)cc1)c1ccccc1</smiles>

N-Desmethyltamoxifen
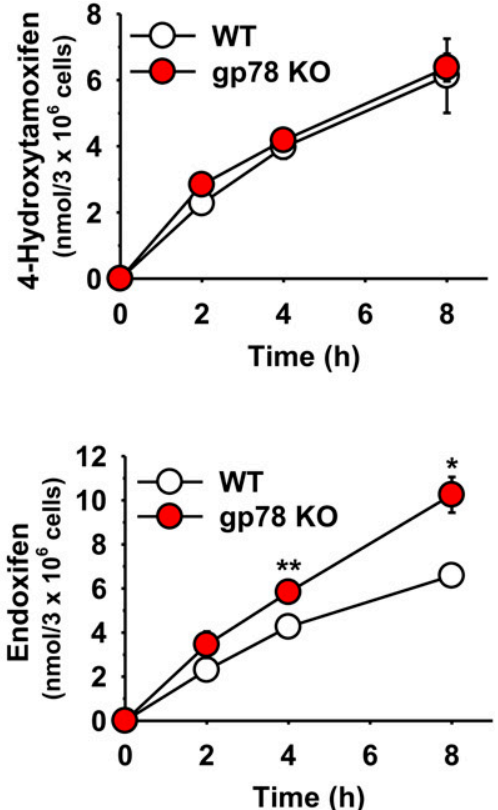

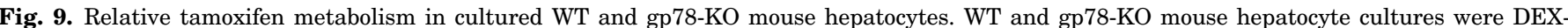

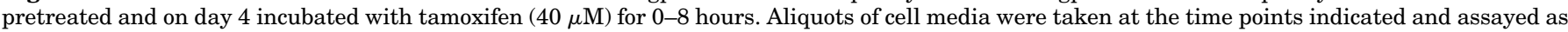

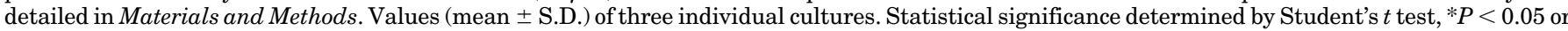
$* * P<0.01$ vs. WT. 
A

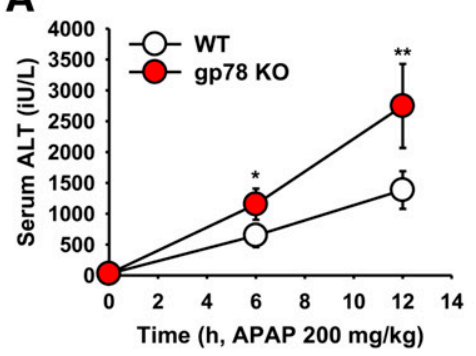

C

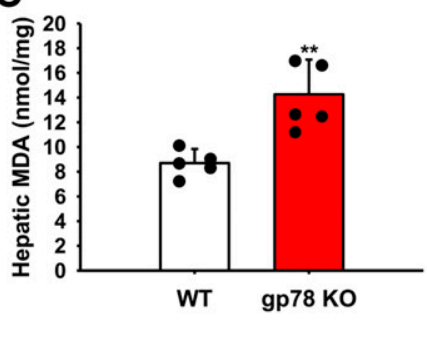

B

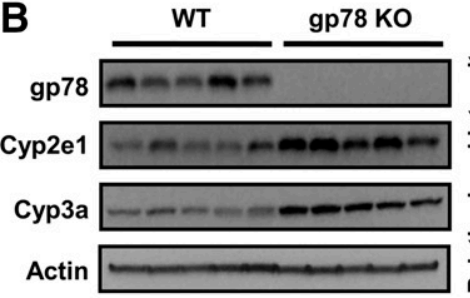

D
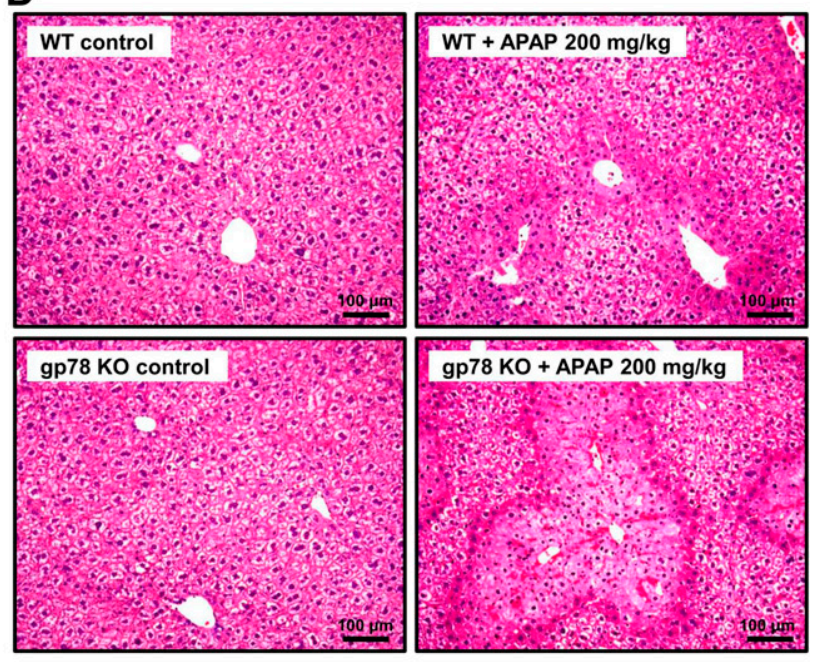

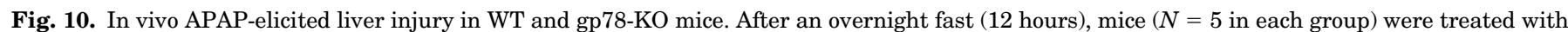

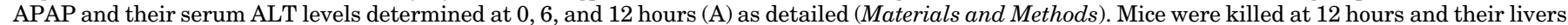

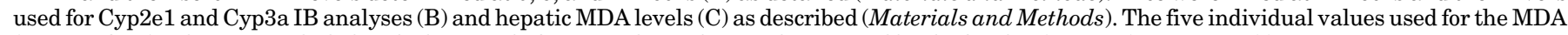

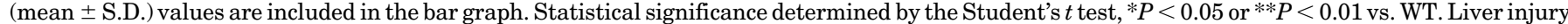

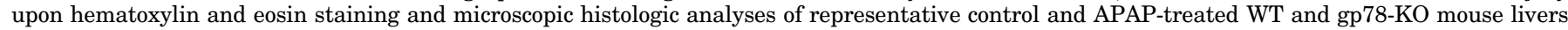
isolated at 12 hours is shown in the right panels (D). ***P $<0.001 \mathrm{vs}$. WT.

functional stabilization of both hepatic Cyp2e1 and Cyps 3a (Figs. 4 and 10).

However, such a functional $\mathrm{P} 450$ protein stabilization can also be beneficial. Thus, our finding of the enhanced bioactivation of the breast cancer chemotherapeutic prodrug tamoxifen in $\mathrm{gp} 78^{-/-}$relative to WT hepatocytes is particularly relevant and noteworthy. The E3 Ub-ligase gp78/AMFR was originally identified as the cell surface receptor for the prometastatic factor autocrine motility factor (Nabi et al., 1990). Later, it was found to function as the E3 Ub-ligase in the ERAD of several substrates, including the tumor metastatic suppressor KAI1 (Fang et al., 2001; Tsai et al., 2007; Chen et al., 2012). Indeed, gp78 levels are highly upregulated within various human tumors (including lung, breast, and colon) and their microenvironments, but not in adjacent normal tissue (Chiu et al., 2008; Fairbank et al., 2009). Importantly, this gp78 upregulation correlates with their invasiveness, the severity of their metastatic progression, and poor prognosis (Chiu et al., 2008; Fairbank et al., 2009). Thus, African-American breast cancer patients, despite their lower breast cancer incidence, exhibit markedly aggressive breast cancer forms and higher mortality rates than their European-American counterparts with lower mortality rates, albeit much higher breast cancer incidence (Chiu et al., 2008; Martin et al., 2009). Gene profiling via mRNA expression analyses revealed that gp78/AMFR is one of the two genes differentially elevated in the breast tumor epithelia and/or stroma of African-American patients versus those of their European-American cohorts. IB analyses documented a correspondingly increased gp78 protein content in these tissues (Martin et al., 2009). Likewise, a transgenic mouse mammary gland gp78-overexpression model also exhibited a hyperplastic phenotype, increased ductal branching, and dense alveolar lobule formation that correlated with its downregulation of the KAI1 metastatic suppressor (Joshi et al., 2010). Thus, given our findings of enhanced Cyp3a-mediated tamoxifen bioactivation upon gp78 KO (Fig. 9), pharmacological attenuation of gp78 function may be therapeutically desirable as an adjuvant to concurrent breast cancer chemotherapy with prodrugs (such as tamoxifen) that are bioactivated by P450s. Plausible adjuvants include aspirin, salicylates, and APAP that activate p38 MAPK-elicited gp78-degradation, resulting in CYP3A23 stabilization (Ohtsuki et al., 2019). However, although such a short-term therapeutic gp78-inhibition strategy warrants consideration, any long-term strategy may be contraindicated given that aged gp78-null mice reportedly develop NASH and human hepatocarcinoma (HHC) (Zhang et al., 2015a).

Over 600 known mammalian E3 Ub-ligases exist that are functionally redundant in substrate recognition and targeting (Metzger et al., 2014), and capable of serving in both E3 and E4 (poly-Ub chain elongation of existing mono-ubiquitinated residues) complementary roles (Morito et al., 2008; Wang et al., 2014; Zhang et al., 2015b; Menzies et al., 2018). Remarkably, despite these well recognized E3 features, the genetic ablation of just a single hepatic E3, gp78/AMFR, is sufficient to stabilize its target substrates, i.e., P450s, with relevant pharmacological/toxic consequences.

Indeed, we recently documented that upon genetic CHIP ablation in mice, hepatic Cyp2e1 was functionally stabilized irrespective of the presence of gp78 and possibly other redundant/complementary E3 Ub-ligases. This underscored the principal role of $\mathrm{UbcH} 5 \mathrm{a} / \mathrm{CHIP} / \mathrm{Hsp} 70$ as the relevant E3 complex in Cyp2e1 proteolytic turnover (Kim et al., 2016a). This functional Cyp2e1 stabilization in vivo led to progressively increased hepatic lipid peroxidation and oxidative stress, JNK activation, and initial hepatic microvesicular steatosis that upon aging developed into macrovesicular steatosis, ushering a full-blown NASH syndrome over a 1year period (Kim et al., 2016a). These findings revealed that abrogation of CHIP-mediated Cyp2e1 ubiquitination not only has acute therapeutic/pharmacological consequences but also severe, long-term pathophysiologic sequelae in mice. 
Surprisingly, comparable Cyp2e1-functional stabilization upon liver-conditional gp78 KO, although toxicologically relevant, did not result in a similar hepatic microvesicular steatosis (D. Kwon and M. A. Correia, preliminary findings). In fact, fructose-induced hepatic triglyceride (TG) and free fatty acid content was statistically significantly lower in gp78 $8^{-/-}$relative to gp $78^{+/+}$hepatocytes. This may stem from two plausible synergistic scenarios: 1) Concurrent stabilization of hepatic Insigs 1 and 2 upon gp78 KO suppresses SREBelicited hepatic lipid biosynthesis as reported in a similar liver-conditional gp78-KO mouse model fed an obesityinducing diet (Liu et al., 2012); and/or 2) the concurrent stabilization upon gp78 KO of apolipoprotein B100, an established gp78 substrate (Liang et al., 2003) critically involved in hepatic VLDL/LDL-packaging and export, accelerates extrahepatic TG export, thereby minimizing the potential for hepatic steatosis. Our observations and those of others (Liu et al., 2012) reveal that upon their liver-conditional gp78 deletion, the mice are leaner and healthier, whereas global genetic gp78 deletion enhances their risk of hepatic steatosis, NASH, and HCC (Zhang et al., 2015a).

Although the gp78/AMFR upregulation in cancerous tissues is widely documented and unequivocal (Chiu et al., 2008; Martin et al., 2009), less clear is whether genetic gp78 polymorphisms normally exist in the general population, engendering correspondingly high and low (defective) gp78 functional phenotypes. The PubMed online human AMFR Gene/dbSNP Variant/Clin Variant databases list various gp78/AMFR allelic variants, and classify some as benign and others as pathologic. Arg/Arg mutations to Arg/Gly or Gly/Gly at "locus 125/145" are claimed to correlate with a higher expression of gp78 mRNA/protein, and correspondingly increased incidence of coronary atherosclerotic disease in a Chinese population (Wang et al., 2018b). The authors indicate that the Arg/Arg residues at "locus" 145 or 125 were affected by the polymorphism. However, the corresponding residues in the human gp78/AMFR primary sequence deposited in PubMed are Val145 and Phe125. The higher incidence of neuroglioblastoma multiformis in an Iranian population has also been associated with an AMFR genetic polymorphism (Eishi Oskouei et al., 2018). The validity of these claims remains however to be verified more extensively. Although the gp78 SNPs listed in the PubMed Database are present along its entire 643 amino acid length, intriguingly, a few pertaining to basic $(\mathrm{K}, \mathrm{R})$ residues in the functional gp78 cytoplasmic domain target the very same positively charged residues that we documented through chemical crosslinking/proteomic analyses and site-directed mutagenesis to be involved in its molecular recognition of CYP3A4 and CYP2E1 acidic phosphodegrons (Wang et al., 2015). Whether any of these listed SNPs truly contribute to genetic gp78-polymorphisms in human populations, and/or correspondingly alter hepatic P450 content and function that trigger DDIs, remains to be elucidated.

In summary, our findings document that the liver-specific genetic ablation of the E3 Ub-ligase gp78/AMFR can result through ERAD disruption in concurrent stabilization of several therapeutically relevant $\mathrm{P} 450$ s with potentially serious, unwarranted therapeutic and/or toxic consequences. Such outcomes could be further aggravated in patients requiring multiple drug therapies for their specific conditions. Whereas for most drugs, accelerated elimination and consequently shortened pharmacological response upon such P450-stabilization may be largely undesirable, this feature could also be ingeniously exploited as a therapeutic strategy in certain instances to enhance the metabolic activation of chemotherapeutic prodrugs with low therapeutic indices.

\section{Acknowledgments}

We thank Chris Her for liver cell isolation at the UCSF Liver Center Core on Cell \& Tissue Biology, and Kevin Siao for histological assistance at the UCSF Liver Center Pathology Core supported by NIDDK Center Grant DK26743. We thank Dr. Alexandra Ioanoviciu for the training in the use of LC-MS system used in the tamoxifen metabolite analyses. We greatly appreciate the contributions of Lisa $\mathrm{Yu}$ and Trisha Mao for LC-MS/MS analyses of nicotine metabolites in cell-culture samples, and funding from NIDA P30 DA012393 (to N. Benowitz, UCSF) for supporting the laboratory resources used for these analyses.

\section{Authorship Contributions}

Participated in research design: Kwon, Kim, Jacob, Correia.

Conducted experiments: Kwon, Kim, Liu.

Contributed new reagents or analytic tools: Kim, Jacob.

Performed data analysis: Kwon, Kim, Jacob.

Wrote or contributed to the writing of the manuscript: Kwon, Jacob, Liu, Correia.

\section{References}

Acharya P, Liao M, Engel JC, and Correia MA (2011) Liver cytochrome P450 3A endoplasmic reticulum-associated degradation: a major role for the p97 AAA ATPase in cytochrome P450 3A extraction into the cytosol. J Biol Chem 286: $3815-3828$

Bajt ML, Knight TR, Lemasters JJ, and Jaeschke H (2004) Acetaminophen-induced oxidant stress and cell injury in cultured mouse hepatocytes: protection by $\mathrm{N}$-acetyl cysteine. Toxicol Sci 80:343-349.

Ballinger CA, Connell P, Wu Y, Hu Z, Thompson LJ, Yin LY, and Patterson C (1999) Identification of CHIP, a novel tetratricopeptide repeat-containing protein that interacts with heat shock proteins and negatively regulates chaperone functions. Mol Cell Biol 19:4535-4545.

Benowitz NL, Dains KM, Dempsey D, Yu L, and Jacob P III (2010) Estimation of nicotine dose after low-level exposure using plasma and urine nicotine metabolites. Cancer Epidemiol Biomarkers Prev 19:1160-1166.

Bhushan B, Walesky C, Manley M, Gallagher T, Borude P, Edwards G, Monga SP, and Apte U (2014) Pro-regenerative signaling after acetaminophen-induced acute liver injury in mice identified using a novel incremental dose model. Am J Pathol 184:3013-3025.

Binkhorst L, Mathijssen RH, Ghobadi Moghaddam-Helmantel IM, de Bruijn P, van Gelder T, Wiemer EA, and Loos WJ (2011) Quantification of tamoxifen and three of its phase-I metabolites in human plasma by liquid chromatography/triple-quadrupole mass spectrometry. J Pharm Biomed Anal 56:1016-1023.

Bradley A, Anastassiadis K, Ayadi A, Battey JF, Bell C, Birling MC, Bottomley J, Brown SD, Bürger A, Bult CJ, et al. (2012) The mammalian gene function resource: the International Knockout Mouse Consortium. Mamm Genome 23:580-586.

Burcham PC and Harman AW (1991) Acetaminophen toxicity results in site-specific mitochondrial damage in isolated mouse hepatocytes. J Biol Chem 266:5049-5054. Cashman JR, Park SB, Yang ZC, Wrighton SA, Jacob P III, and Benowitz NL (1992) Metabolism of nicotine by human liver microsomes: stereoselective formation of trans-nicotine $\mathrm{N}^{\prime}$-oxide. Chem Res Toxicol 5:639-646.

Chang TKH and Waxman DJ (1996) The CYP2A subfamily, in Cytochromes P450: Metabolic and Toxicological Aspects (Ionnides C ed) pp 99-134, CRC Press, Boca Raton, FL.

Chen B, Mariano J, Tsai YC, Chan AH, Cohen M, and Weissman AM (2006) The activity of a human endoplasmic reticulum-associated degradation E3, gp78, requires its Cue domain, RING finger, and an E2-binding site. Proc Natl Acad Sci USA 103:341-346.

Chen Z, Du S, and Fang S (2012) gp78: a multifaceted ubiquitin ligase that integrates a unique protein degradation pathway from the endoplasmic reticulum. Curr Protein Pept Sci 13:414-424.

Chiu CG, St-Pierre P, Nabi IR, and Wiseman SM (2008) Autocrine motility factor receptor: a clinical review. Expert Rev Anticancer Ther 8:207-217.

Christianson JC and Ye Y (2014) Cleaning up in the endoplasmic reticulum: ubiquitin in charge. Nat Struct Mol Biol 21:325-335.

Connell P, Ballinger CA, Jiang J, Wu Y, Thompson LJ, Höhfeld J, and Patterson C (2001) The co-chaperone CHIP regulates protein triage decisions mediated by heatshock proteins. Nat Cell Biol 3:93-96.

Correia MA (2018) Drug biotransformation, in Basic and Clinical Pharmacology (Katzung BG ed) pp 56-73, McGraw Hill \& Lange.

Correia MA, Davoll SH, Wrighton SA, and Thomas PE (1992) Degradation of rat liver cytochromes P450 3A after their inactivation by 3,5-dicarbethoxy-2,6-dimethyl-4ethyl-1,4-dihydropyridine: characterization of the proteolytic system. Arch Biochem Biophys 297:228-238. 
Dahmane E, Mercier T, Zanolari B, Cruchon S, Guignard N, Buclin T, Leyvraz S, Zaman K, Csajka C, and Decosterd LA (2010) An ultra performance liquid chromatography-tandem MS assay for tamoxifen metabolites profiling in plasma: first evidence of $4^{\prime}$-hydroxylated metabolites in breast cancer patients. J Chromatogr B Analyt Technol Biomed Life Sci 878:3402-3414.

Desta Z, Ward BA, Soukhova NV, and Flockhart DA (2004) Comprehensive evaluation of tamoxifen sequential biotransformation by the human cytochrome P450 system in vitro: prominent roles for CYP3A and CYP2D6. J Pharmacol Exp Ther 310:1062-1075.

Donato MT, Jiménez N, Castell JV, and Gómez-Lechón MJ (2004) Fluorescencebased assays for screening nine cytochrome P450 (P450) activities in intact cells expressing individual human P450 enzymes. Drug Metab Dispos 32:699-706.

Eishi Oskouei A, Rafiee L, Mahzouni P, Gharipour M, and Javanmard SH (2018) Association between autocrine motility factor receptor gene polymorphism (rs2440472, rs373191257) and glioblastoma multiform in a representative Iranian population. J Res Med Sci 23:96.

Eliasson E, Mkrtchian S, Halpert JR, and Ingelman-Sundberg M (1994) Substrateregulated, cAMP-dependent phosphorylation, denaturation, and degradation of glucocorticoid-inducible rat liver cytochrome P450 3A1. J Biol Chem 269: 18378-18383.

Eliasson E, Mkrtchian S, and Ingelman-Sundberg M (1992) Hormone- and substrateregulated intracellular degradation of cytochrome P450 (2E1) involving MgATPactivated rapid proteolysis in the endoplasmic reticulum membranes. J Biol Chem 267:15765-15769.

Fairbank M, St-Pierre P, and Nabi IR (2009) The complex biology of autocrine motility factor/phosphoglucose isomerase (AMF/PGI) and its receptor, the gp78/AMFR E3 ubiquitin ligase. Mol Biosyst 5:793-801.

Fang S, Ferrone M, Yang C, Jensen JP, Tiwari S, and Weissman AM (2001) The tumor autocrine motility factor receptor, gp78, is a ubiquitin protein ligase implicated in degradation from the endoplasmic reticulum. Proc Natl Acad Sci USA 98:14422-14427.

Faouzi S, Medzihradszky KF, Hefner C, Maher JJ, and Correia MA (2007) Characterization of the physiological turnover of native and inactivated cytochromes P450 3A in cultured rat hepatocytes: a role for the cytosolic AAA ATPase p97? Biochemistry 46:7793-7803.

Gillette JR, Nelson SD, Mulder GJ, Jollow DJ, Mitchell JR, Pohl LR, and Hinson JA (1981) Formation of chemically reactive metabolites of phenacetin and acetaminophen. Adv Exp Med Biol 136 (Pt B):931-950.

Girre C, Lucas D, Hispard E, Menez C, Dally S, and Menez JF (1994) Assessment of cytochrome P4502E1 induction in alcoholic patients by chlorzoxazone pharmacokinetics. Biochem Pharmacol 47:1503-1508.

Goetz MP, Knox SK, Suman VJ, Rae JM, Safgren SL, Ames MM, Visscher DW, Reynolds C, Couch FJ, Lingle WL, et al. (2007) The impact of cytochrome P450 2D6 metabolism in women receiving adjuvant tamoxifen. Breast Cancer Res Treat 101: 113-121.

Guengerich FP (2015) Human cytochrome P450 enzymes, in Cytochrome P450: Structure, Mechanism and Biochemistry (Ortiz de Montellano P ed) pp 523-785, Springer International publishing, New York

Han XM, Lee G, Hefner C, Maher JJ, and Correia MA (2005) Heme-reversible impairment of CYP2B1/2 induction in heme-depleted rat hepatocytes in primary culture: translational control by a hepatic alpha-subunit of the eukaryotic initiation factor kinase? J Pharmacol Exp Ther 314:128-138.

Hukkanen J, Jacob P III, and Benowitz NL (2005) Metabolism and disposition kinetics of nicotine. Pharmacol Rev 57:79-115.

Jacob P III, Yu L, Duan M, Ramos L, Yturralde O, and Benowitz NL (2011) Determination of the nicotine metabolites cotinine and trans-3'-hydroxycotinine in biologic fluids of smokers and non-smokers using liquid chromatography-tandem mass spectrometry: biomarkers for tobacco smoke exposure and for phenotyping cytochrome P450 2A6 activity. J Chromatogr B Analyt Technol Biomed Life Sci 879:267-276.

Jacolot F, Simon I, Dreano Y, Beaune P, Riche C, and Berthou F (1991) Identification of the cytochrome P450 IIIA family as the enzymes involved in the N-demethylation of tamoxifen in human liver microsomes. Biochem Pharmacol 41:1911-1919.

Jiang J, Ballinger CA, Wu Y, Dai Q, Cyr DM, Höhfeld J, and Patterson C (2001) CHIP is a U-box-dependent E3 ubiquitin ligase: identification of Hsc70 as a target for ubiquitylation. J Biol Chem 276:42938-42944.

Joshi B, Li L, and Nabi IR (2010) A role for KAI1 in promotion of cell proliferation and mammary gland hyperplasia by the gp78 ubiquitin ligase. J Biol Chem 285 $8830-8839$.

Joshi V, Upadhyay A, Kumar A, and Mishra A (2017) Gp78 E3 ubiquitin ligase: essential functions and contributions in proteostasis. Front Cell Neurosci 11:259.

Kim SM, Acharya P, Engel JC, and Correia MA (2010) Liver cytochrome P450 3A ubiquitination in vivo by gp78/autocrine motility factor receptor and $\mathrm{C}$ terminus of Hsp70-interacting protein (CHIP) E3 ubiquitin ligases: physiological and pharmacological relevance. J Biol Chem 285:35866-35877.

Kim SM, Grenert JP, Patterson C, and Correia MA (2016a) $\left.\mathrm{CHIP}^{\left(-{ }^{-}\right)}\right)$-mouse liver: adiponectin-AMPK-FOXO-activation overrides CYP2e1-elicited JNK1-activation, delaying onset of NASH: therapeutic implications. Sci Rep 6:29423.

Kim SM, Wang Y, Nabavi N, Liu Y, and Correia MA (2016b) Hepatic cytochromes P450: structural degrons and barcodes, posttranslational modifications and cellular adapters in the ERAD-endgame. Drug Metab Rev 48:405-433.

Lee SS, Buters JT, Pineau T, Fernandez-Salguero P, and Gonzalez FJ (1996) Role of CYP2E1 in the hepatotoxicity of acetaminophen. J Biol Chem 271:12063-12067.

Li W, Tu D, Brunger AT, and Ye Y (2007) A ubiquitin ligase transfers preformed polyubiquitin chains from a conjugating enzyme to a substrate. Nature 446: 333-337.

Liang JS, Kim T, Fang S, Yamaguchi J, Weissman AM, Fisher EA, and Ginsberg HN (2003) Overexpression of the tumor autocrine motility factor receptor Gp78, a ubiquitin protein ligase, results in increased ubiquitinylation and decreased secretion of apolipoprotein B100 in HepG2 cells. J Biol Chem 278:23984-23988.
Liao M, Faouzi S, Karyakin A, and Correia MA (2006) Endoplasmic reticulumassociated degradation of cytochrome P450 CYP3A4 in Saccharomyces cerevisiae further characterization of cellular participants and structural determinants. Mol Pharmacol 69:1897-1904.

Liu TF, Tang JJ, Li PS, Shen Y, Li JG, Miao HH, Li BL, and Song BL (2012) Ablation of gp78 in liver improves hyperlipidemia and insulin resistance by inhibiting SREBP to decrease lipid biosynthesis. Cell Metab 16:213-225.

Martin DN, Boersma BJ, Yi M, Reimers M, Howe TM, Yfantis HG, Tsai YC, Williams EH, Lee DH, Stephens RM, et al. (2009) Differences in the tumor microenvironment between African-American and European-American breast cancer patients. PLoS One 4:e4531.

McGill MR, Lebofsky M, Norris HR, Slawson MH, Bajt ML, Xie Y, Williams CD, Wilkins DG, Rollins DE, and Jaeschke H (2013) Plasma and liver acetaminophenprotein adduct levels in mice after acetaminophen treatment: dose-response, mechanisms, and clinical implications. Toxicol Appl Pharmacol 269:240-249.

Menzies SA, Volkmar N, van den Boomen DJ, Timms RT, Dickson AS, Nathan JA and Lehner PJ (2018) The sterol-responsive RNF145 E3 ubiquitin ligase mediates the degradation of HMG-CoA reductase together with gp78 and Hrd1. eLife 7: e40009, doi: 10.7554/eLife.40009.

Metzger MB, Pruneda JN, Klevit RE, and Weissman AM (2014) RING-type E3 ligases: master manipulators of E2 ubiquitin-conjugating enzymes and ubiquitination. Biochim Biophys Acta 1843:47-60.

Mitchell JR, Jollow DJ, Potter WZ, Davis DC, Gillette JR, and Brodie BB (1973) Acetaminophen-induced hepatic necrosis. I. Role of drug metabolism. J Pharmacol Exp Ther 187:185-194.

Morishima Y, Peng HM, Lin HL, Hollenberg PF, Sunahara RK, Osawa Y, and Pratt WB (2005) Regulation of cytochrome P450 2E1 by heat shock protein 90-dependent stabilization and CHIP-dependent proteasomal degradation. Biochemistry 44 $16333-16340$

Morito D, Hirao K, Oda Y, Hosokawa N, Tokunaga F, Cyr DM, Tanaka K, Iwai K, and Nagata K (2008) Gp78 cooperates with RMA1 in endoplasmic reticulumassociated degradation of CFTRDeltaF508. Mol Biol Cell 19:1328-1336.

Murata S, Minami Y, Minami M, Chiba T, and Tanaka K (2001) CHIP is a chaperonedependent E3 ligase that ubiquitylates unfolded protein. EMBO Rep 2:1133-1138.

Nabi IR, Watanabe H, and Raz A (1990) Identification of B16-F1 melanoma autocrine motility-like factor receptor. Cancer Res 50:409-414.

Nakajima M, Yamamoto T, Nunoya K, Yokoi T, Nagashima K, Inoue K, Funae Y, Shimada N, Kamataki T, and Kuroiwa Y (1996) Role of human cytochrome P4502A6 in C-oxidation of nicotine. Drug Metab Dispos 24:1212-1217.

Needham PG, Guerriero CJ, and Brodsky JL (2019) Chaperoning endoplasmic reticulum-associated degradation (ERAD) and protein conformational diseases Cold Spring Harb Perspect Biol 11:a033928, doi: 10.1101/cshperspect.a033928.

Nelson SD (1990) Molecular mechanisms of the hepatotoxicity caused by acetaminophen. Semin Liver Dis 10:267-278.

Ohtsuki Y, Sanoh S, Santoh M, Ejiri Y, Ohta S, and Kotake Y (2019) Inhibition of cytochrome $\mathrm{P} 450$ 3A protein degradation and subsequent increase in enzymatic activity through p38 MAPK activation by acetaminophen and salicylate derivatives. Biochem Biophys Res Commun 509:287-293.

Olzmann JA, Kopito RR, and Christianson JC (2013) The mammalian endoplasmic reticulum-associated degradation system. Cold Spring Harb Perspect Biol 5 a013185.

Pabarcus MK, Hoe N, Sadeghi S, Patterson C, Wiertz E, and Correia MA (2009) CYP3A4 ubiquitination by gp78 (the tumor autocrine motility factor receptor, AMFR) and CHIP E3 ligases. Arch Biochem Biophys 483:66-74.

Peer CJ, Sissung TM, and Figg WD (2011) CHIP and gp78-mediated ubiquitination of CYP3A4: implications for the pharmacology of anticancer agents. Cancer Biol Ther 11:549-551.

Postic C and Magnuson MA (2000) DNA excision in liver by an albumin-Cre transgene occurs progressively with age. Genesis 26:149-150

Preston GM and Brodsky JL (2017) The evolving role of ubiquitin modification in endoplasmic reticulum-associated degradation. Biochem $J$ 474:445-469.

Schimke RT and Doyle D (1970) Control of enzyme levels in animal tissues. Annu Rev Biochem 39:929-976.

Siu EC, Wildenauer DB, and Tyndale RF (2006) Nicotine self-administration in mice is associated with rates of nicotine inactivation by CYP2A5. Psychopharmacology (Berl) 184:401-408.

Skarnes WC, Rosen B, West AP, Koutsourakis M, Bushell W, Iyer V, Mujica AO, Thomas M, Harrow J, Cox T, et al. (2011) A conditional knockout resource for the genome-wide study of mouse gene function. Nature 474:337-342.

Tsai YC, Mendoza A, Mariano JM, Zhou M, Kostova Z, Chen B, Veenstra T, Hewitt SM, Helman LJ, Khanna C, et al. (2007) The ubiquitin ligase gp78 promotes sarcoma metastasis by targeting KAI1 for degradation. Nat Med 13:1504-1509.

Wang HF, Figueiredo Pereira ME, and Correia MA (1999) Cytochrome P450 3A degradation in isolated rat hepatocytes: $26 \mathrm{~S}$ proteasome inhibitors as probes. Arch Biochem Biophys 365:45-53.

Wang L, Bernert JT, Benowitz NL, Feng J, Jacob P III, McGahee E, Caudill SP, Scherer G, Scherer M, Pluym N, et al. (2018a) Collaborative method performance study of the measurement of nicotine, its metabolites, and total nicotine equivalents in human urine. Cancer Epidemiol Biomarkers Prev 27: 1083-1090.

Wang L, Li HC, Zhou J, Yang B, Qiao CD, Liu YM, and Zhang Z (2018b) Correlation between the GP78 gene polymorphism and coronary atherosclerotic heart disease. Hellenic J Cardiol 59:8-13.

Wang X, Medzihradszky KF, Maltby D, and Correia MA (2001) Phosphorylation of native and heme-modified CYP3A4 by protein kinase C: a mass spectrometric characterization of the phosphorylated peptides. Biochemistry 40:11318-11326.

Wang Y, Guan S, Acharya P, Koop DR, Liu Y, Liao M, Burlingame AL, and Correia MA (2011) Ubiquitin-dependent proteasomal degradation of human liver cytochrome P450 2E1: identification of sites targeted for phosphorylation and ubiquitination. J Biol Chem 286:9443-9456. 
Wang Y, Guan S, Acharya P, Liu Y, Thirumaran RK, Brandman R, Schuetz EG, Burlingame AL, and Correia MA (2012) Multisite phosphorylation of human liver cytochrome P450 3A4 enhances Its gp78- and CHIP-mediated ubiquitination: a pivotal role of its Ser478 residue in the gp78-catalyzed reaction. Mol Cell Proteomics 11:M111.010132.

Wang Y, Ha SW, Zhang T, Kho DH, Raz A, and Xie Y (2014) Polyubiquitylation of AMF requires cooperation between the gp78 and TRIM25 ubiquitin ligases. Oncotarget 5:2044-2051.

Wang Y, Kim SM, Trnka MJ, Liu Y, Burlingame AL, and Correia MA (2015) Human liver cytochrome P450 3A4 ubiquitination: molecular recognition by UBC7-gp78 autocrine motility factor receptor and UbcH5a-CHIP-Hsc70-Hsp40 E2-E3 ubiquitin ligase complexes. J Biol Chem 290:3308-3332.

Wang Y, Liao M, Hoe N, Acharya P, Deng C, Krutchinsky AN, and Correia MA (2009) A role for protein phosphorylation in cytochrome P450 3A4 ubiquitin-dependent proteasomal degradation. J Biol Chem 284:5671-5684.

Wolf KK, Wood SG, Allard JL, Hunt JA, Gorman N, Walton-Strong BW, Szakacs JG Duan SX, Hao Q, Court MH, et al. (2007) Role of CYP3A and CYP2E1 in alcoholmediated increases in acetaminophen hepatotoxicity: comparison of wild-type and Cyp2e1(-/-) mice. Drug Metab Dispos 35:1223-1231.

Yuan JM, Nelson HH, Carmella SG, Wang R, Kuriger-Laber J, Jin A, Adams-Haduch J, Hecht SS, Koh WP, and Murphy SE (2017) CYP2A6 genetic polymorphisms and biomarkers of tobacco smoke constituents in relation to risk of lung cancer in the Singapore Chinese Health Study. Carcinogenesis 38:411-418.

Zhang T, Kho DH, Wang Y, Harazono Y, Nakajima K, Xie Y, and Raz A (2015a) Gp78, an E3 ubiquitin ligase acts as a gatekeeper suppressing nonalcoholic steatohepatitis (NASH) and liver cancer. PLoS One 10:e0118448.
Zhang T, Xu Y, Liu Y, and Ye Y (2015b) gp78 functions downstream of Hrd1 to promote degradation of misfolded proteins of the endoplasmic reticulum. Mol Biol Cell 26:4438-4450.

Zhong X, Shen Y, Ballar P, Apostolou A, Agami R, and Fang S (2004) AAA ATPase p97/valosin-containing protein interacts with gp78, a ubiquitin ligase for endoplasmic reticulum-associated degradation. $J$ Biol Chem $\mathbf{2 7 9}$ 45676-45684.

Zhou X, D'Agostino J, Xie F, and Ding X (2012) Role of CYP2A5 in the bioactivation of the lung carcinogen 4-(methylnitrosamino)-1-(3-pyridyl)-1-butanone in mice. $J$ Pharmacol Exp Ther 341:233-241.

Zhou X, Zhuo X, Xie F, Kluetzman K, Shu YZ, Humphreys WG, and Ding X (2010) Role of CYP2A5 in the clearance of nicotine and cotinine: insights from studies on a Cyp2a5-null mouse model. J Pharmacol Exp Ther 332:578-587.

Zhu AZ, Binnington MJ, Renner CC, Lanier AP, Hatsukami DK, Stepanov I, Watson CH, Sosnoff CS, Benowitz NL, and Tyndale RF (2013) Alaska native smokers and smokeless tobacco users with slower CYP2A6 activity have lower tobacco consumption, lower tobacco-specific nitrosamine exposure and lower tobacco-specific nitrosamine bioactivation. Carcinogenesis 34:93-101.

Address correspondence to: Dr. Maria Almira Correia, Cellular \& Molecular Pharmacology, University of California San Francisco, Genentech Hall, 600 16th Street, Box 2280, San Francisco, CA 94158-2517. E-mail: almira.correia@ucsf.edu 